\title{
RESEARCH
}

Open Access

\section{SAR228810: an antibody for protofibrillar amyloid $\beta$ peptide designed to reduce the risk of amyloid-related imaging abnormalities (ARIA)}

Laurent Pradier ${ }^{1 *}$ (D), Véronique Blanchard-Brégeon ${ }^{1}$, Andrees Bohme ${ }^{1}$, Thomas Debeir ${ }^{1}$, Jean Menager ${ }^{1}$, Patrick Benoit ${ }^{1}$, Pascal Barneoud ${ }^{1}$, Véronique Taupin ${ }^{1}$, Philippe Bertrand ${ }^{1}$, Philippe Dugay ${ }^{1}$, Béatrice Cameron ${ }^{2}$, Yi Shi ${ }^{2}$, Souad Naimi ${ }^{2}$, Marc Duchesne ${ }^{2}$, Marie Gagnaire ${ }^{2}$, Tim Weeden ${ }^{3,7}$, Tara Travaline ${ }^{3}$, David Reczek ${ }^{3}$, Leonard Khiroug ${ }^{4}$, Mohamed Slaoui ${ }^{5}$, Pascale Brunel ${ }^{5}$, Hidehiro Fukuyama ${ }^{6,8}$, Jeffrey Ravetch ${ }^{6}$, Thierry Canton ${ }^{1}$ and Caroline Cohen'

\begin{abstract}
Background: Anti-amyloid $\beta$ (AB) immunotherapy represents a major area of drug development for Alzheimer's disease (AD). However, A $\beta$ peptide adopts multiple conformations and the pathological forms to be specifically targeted have not been identified. $A \beta$ immunotherapy-related vasogenic edema has also been severely dose limiting for antibodies with effector functions binding vascular amyloid such as bapineuzumab. These two factors might have contributed to the limited efficacy demonstrated so far in clinical studies.
\end{abstract}

Methods: To address these limitations, we have engineered SAR228810, a humanized monoclonal antibody (mAb) with limited Fc effector functions that binds specifically to soluble protofibrillar and fibrillar forms of AB peptide and we tested it together with its murine precursor SAR255952 in vitro and in vivo.

Results: Unlike gantenerumab and BAN2401, SAR228810 and SAR255952 do not bind to A $\beta$ monomers, low molecular weight $A \beta$ oligomers or, in human brain sections, to $A \beta$ diffuse deposits which are not specific of $A D$ pathology. Both antibodies prevent Aß42 oligomer neurotoxicity in primary neuronal cultures. In vivo, SAR255952, a mouse aglycosylated lgG1, dose-dependently prevented brain amyloid plaque formation and plaque-related inflammation with a minimal active dose of $3 \mathrm{mg} / \mathrm{kg} /$ week by the intraperitoneal route. No increase in plasma $A \beta$ levels was observed with SAR255952 treatment, in line with its lack of affinity for monomeric A . The effects of SAR255952 translated into synaptic functional improvement in ex-vivo hippocampal slices. Brain penetration and decoration of cerebral amyloid plaques was documented in live animals and postmortem. SAR255952 (up to 50 $\mathrm{mg} / \mathrm{kg} /$ week intravenously) did not increase brain microhemorrhages and/or microscopic changes in meningeal and cerebral arteries in old APPSL mice while 3D6, the murine version of bapineuzumab, did. In immunotolerized mice, the clinical candidate SAR228810 demonstrated the same level of efficacy as the murine SAR255952.

Conclusion: Based on the improved efficacy/safety profile in non-clinical models of SAR228810, a first-in-man single and multiple dose administration clinical study has been initiated in AD patients.

Keywords: Alzheimer's disease, Anti-A $\beta$ immunotherapy, Protofibrillar A $\beta$ peptide

\footnotetext{
* Correspondence: laurent.pradier@sanofi.com

${ }^{1}$ Sanofi R\&D Neuroscience Unit, Sanofi, 1Av P. Brossolette, 91385

Chilly-Mazarin, France

Full list of author information is available at the end of the article
}

(c) The Author(s). 2018 Open Access This article is distributed under the terms of the Creative Commons Attribution 4.0 International License (http://creativecommons.org/licenses/by/4.0/), which permits unrestricted use, distribution, and reproduction in any medium, provided you give appropriate credit to the original author(s) and the source, provide a link to the Creative Commons license, and indicate if changes were made. The Creative Commons Public Domain Dedication waiver (http://creativecommons.org/publicdomain/zero/1.0/) applies to the data made available in this article, unless otherwise stated. 


\section{Background}

Alzheimer's disease (AD) is a progressive dementia, neuropathologically characterized by deposits of extracellular $A \beta$ plaques and intraneuronal fibrillary tangles which contain hyperphosphorylated tau protein. Additional pathological changes in the brain include gliosis, inflammation, neuritic dystrophy, neuron loss, and changes in neurotransmitter levels [1].

Genetic evidence supports the key role of amyloid $\beta$ $(A \beta)$ peptide in the pathogenesis of $A D: 1)$ all mutations causing familial $\mathrm{AD}$ increase the production of $\mathrm{A} \beta 42$ or the ratio of $A \beta 42$ to the less aggregation-prone $A \beta 40$ form [2]; and 2) genetic variants that reduce $A \beta$ production lower the risk of developing $\mathrm{AD}$ [3]. However, anti-A $\beta$ /amyloid strategies have not yet translated into an efficient and safe treatment for AD (reviewed in [4]). The recent interruption for futility of the phase III clinical study of BACE inhibitor verubescestat (Merck, MSD [5]) in prodromal AD subjects indicates that blocking the production of $A \beta$ monomer is not efficacious at a disease stage when brain amyloid has been accumulating for at least a decade [6]. Quite differently, $A \beta$ immunotherapy has the potential to neutralize or clear brain amyloid and therefore be of therapeutic value even later in the course of pathology progression than $A \beta$ production inhibitors. However, after more than a decade of active development, encouraging clinical results have only recently been obtained. Immunotherapy failures thus far have been attributed in part to: 1) the dose severely limited by safety issues (vasogenic edema/microhemorrhage associated with amyloid-related imaging abnormalities (ARIA) reported in clinical settings, thus preventing efficacious brain levels being reached); 2) not targeting the appropriate toxic $A \beta$ species; and 3) intervention late in the disease continuum. More promising results were recently generated with three antibodies binding to protofibrillar $A \beta$ (aducanumab [7], gantenerumab [8, 9], and BAN2401 [10]) on biomarker endpoints that will need to be confirmed in larger ongoing clinical studies.

$\mathrm{A} \beta$ peptide can adopt multiple assembly forms and conformations which are operationally defined but with limited biophysical characterization, and include monomer, oligomer, soluble protofibrils of high molecular weight, and insoluble aggregated plaques (reviewed in detail in [11]). Which form of $A \beta$, if any single one, contributes to the disease remains controversial. From brain pathology studies, soluble oligomeric forms of $\mathrm{A} \beta$ (oA $\beta$ ) have attracted attention since levels are correlated with AD dementia stage [12-14] and AD brain-derived soluble $A \beta$ fractions lead to acute inhibition of synaptic plasticity and, over days, disruption of neurite integrity [15-18]. Synaptotoxicity is mediated by high molecular weight $\mathrm{A} \beta$ assemblies (oligomeric or protofibrillar forms) that continue to be further analyzed [19, 20]. Amyloid plaques and oligomers could possibly be intimately associated and in dynamic equilibrium, with evidence now suggesting that plaques could act as reservoir or as a nidus for $A \beta$ oligomerization that could impair local synapses [21]. In this regard, inhibiting $A \beta$ production (with a BACE1 inhibitor, for example) when amyloid plaques are already present would not prevent leakage of $\mathrm{A} \beta$ oligomers from plaques. The issue of which $\mathrm{A} \beta$ assembly to target is also quite important in view of the large differences in concentration of those species in the brain. Monomeric $\mathrm{A} \beta$ is abundant, with cerebrospinal fluid (CSF) concentrations of approximately $10 \mathrm{ng} / \mathrm{ml}$ $(2.5 \mathrm{nM})$, and amyloid plaques can represent up to micromolar concentration of $\mathrm{A} \beta$ in brain tissue [22]. In comparison, soluble oligomeric and protofibrillar $\mathrm{A} \beta$ forms in CSF have been quantified in the low pM range with different detection techniques (approximately $3 \mathrm{pg} /$ $\mathrm{ml}$ [23], $1 \mathrm{pg} / \mathrm{ml}$ [24], and below the limit of quantitation (LOQ) $6.25 \mathrm{pg} / \mathrm{ml}$ [14]; reviewed in [25]).

The different anti-A $\beta$ monoclonal antibodies (mAbs) in clinical development have varying $A \beta$ conformation binding profiles (reviewed in [4]). Solanezumab binds essentially to soluble monomeric $A \beta$; bapineuzumab and crenezumab bind to all $A \beta$ conformation, while gantenerumab, BAN-2401, and the more recently described aducanumab bind to a large spectrum of oligomeric to fibrillar forms of $A \beta$, but with much lower affinity to monomeric $A \beta$. Precise differentiation among the latter three is quite limited due in part to the poor definition of the multiple $\mathrm{A} \beta$ oligomeric forms. In vivo, antibodies with limited differentiation among $A \beta$ assemblies (bapineuzumab and crenezumab) would be preferentially engaged with the most abundant monomeric and insoluble $\mathrm{A} \beta$ fibrillar forms, leading to poor brain bioavailability to neutralize soluble oligomeric and protofibrillar forms. The monoclonal bioavailability issue in the brain is critical due to the detectable but very low brain penetration of therapeutic immunoglobulin Gs (IgGs) and is further exacerbated by the ARIA-related dose limitations.

In clinical trials, several anti-A $\beta$ mAbs have elicited adverse events: vasogenic edema/microhemorrhage associated with amyloid-related imaging abnormalities (ARIA) in particular in ApoE4 carriers that are probably related to binding onto vascular amyloid, and local recruitment of an immune response via mAb Fc effector functions (reviewed in [26]). With regard to this point, crenezumab has been engineered on a human IgG4 Fc domain endowed with partially reduced effector functions leading to lower incidence of ARIA at higher doses than bapineuzumab [27], and exploratory post-hoc analysis suggested an effect on cognitive decline in an early $\mathrm{AD}$ subgroup. While deleterious regarding ARIA, the contribution of $\mathrm{mAb}$ effector functions to efficacy is quite controversial and it has been suggested that they were not necessary for in-vivo efficacy in animal models [28]. 
To address some of the aforementioned shortcomings of current $A \beta$ mAbs, a humanized monoclonal antibody SAR228810 has been designed. Its key differentiating attributes are the specific pathology-associated antigen targeted soluble protofibrillar and fibrillar $\mathrm{A} \beta$, and its drastically reduced effector functions (with two silencing mutations on a human IgG4 backbone) leading to improved benefit/ risk balance. By targeting protofibrillar $\mathrm{A} \beta$ and not monomers, SAR228810 should be more effective in preventing plaque formation and oligomer-induced synaptic dysfunction and neurite loss than antibodies binding additionally to $A \beta$ monomer. Here, we describe the in-vitro profile of SAR228810 (currently in phase 1 in AD patients) and its murine precursor SAR255952, a mouse monoclonal aglycosylated IgG1 antibody, comparing them with other protofibrillar A $\beta$ antibodies gantenerumab and BAN2401 and their in-vivo activity compared with mouse bapineuzumab.

\section{Methods}

\section{Antibody preparation}

SAR255952 is an aglycosylated variant of A $\beta$ protofibrilspecific murine IgG1 antibody 13C3 [29] (patent application WO2009/065054) generated by mutation of the glycosylation site asparagine 297 to alanine in the Fc domain (N297A; position according to Kabat's nomenclature). SAR228810 is a humanized version of SAR255952 with an engineered human IgG4 framework containing two amino-acid substitutions described to reduce half molecules (S241P) and effector functions (L248E [30]), as described in patent application WO2010/130946. An IgG1 mouse monoclonal antibody (Ctl-IgG1) against a nonmammalian protein was used as a negative control. The comparator is 3D6, the murine IgG2b version of bapineuzumab, directed against the $\mathrm{N}$-term extremity of $\mathrm{A} \beta$ and insensitive to the assembly state of $\mathrm{A} \beta$ peptide [31].

\section{Production and quality control}

Antibodies were produced by transient transfection in human embryonic kidney cell line FreeStyle 293-F (Invitrogen) or from recombinant stable $\mathrm{CHO}$ cell lines. Briefly, cell culture supernatants were purified by a two-step protocol including affinity chromatography on protein A (MabSelect GE Healthcare) and CHT Ceramic Hydroxyapatite (Bio-Rad), and then formulated in phosphate-buffered saline (PBS; Dulbecco, reference $14,190-094)$ and sterile filtered $(0.2 \mu \mathrm{m})$. Purity was estimated above $98 \%$ by SDS-PAGE under denaturing conditions and by size exclusion chromatography. The mass measured by LC/MS was in agreement with the amino acid sequence and the lack of N-glycans on the Fc domain for SAR255952 as expected. The apparent mass obtained by SDS-PAGE under nondenaturing conditions and by size exclusion chromatography was in agreement with the heterotetrameric structure of antibodies 150
$\mathrm{kDa}$ for SAR255952 and $160 \mathrm{kDa}$ for the other glycosylated IgGs. For in-vitro studies, the following antibodies/batches were used: SAR228810 (C1024149), SAR255952 (batch 255,952-F04-015), BAN-2401 (batch VA214212), gantenerumab (batch VA214182), and their respective control isotypes: human IgG4 (hyb_CAA162_IgG4; batch VA112104), mouse Ctrl-IgG1 (hyb_CAA162_IgG1; batch VA213009), and human IgG1 (VA214053). For in-vivo studies the following antibodies and batches were used: SAR255952 (batch LP08190, control isotype Ctrl-IgG1 (hyb_CAA162_IgG1; batch LP09022), mouse 3D6-bapineuzu mab (LP08030), and SAR228810 (LP09124). All batches were tested for sterility and lack of endotoxins.

\section{Synthetic $A \beta$ preparations}

Protofibrillar and low molecular weight (LMW) forms of A $31-42$ were prepared as described previously [32]. Briefly, A $\beta 1-42$ (Anaspec, reference 20,276) was dissolved in $10 \mathrm{mM} \mathrm{NaOH}$ at $100 \mu \mathrm{M}$ and aliquots were stored at $-80{ }^{\circ} \mathrm{C}$. The sample was thawed on ice for $10 \mathrm{~min}$ and then diluted to $50 \mu \mathrm{M}$ in $\mathrm{NaCl} / \mathrm{Pi}$ buffer and incubated overnight at $37^{\circ} \mathrm{C}$. The sample was centrifuged at $17,900 \mathrm{~g}$ for $5 \mathrm{~min}$ at $16^{\circ} \mathrm{C}$ and the supernatant was immediately collected. Protofibrils were separated from the LMW A $\beta$ forms by size exclusion chromatography (SEC), and $500 \mu \mathrm{l}$ of supernatant was loaded onto the Superdex 75 and fractions of $125 \mu \mathrm{l}$ were collected. The concentration of protofibrillar (exclusion volume) and LMW fractions were determined by Bradford assay in reference to a standard curve established with peptide A $\beta 1-42$.

\section{Preparation of fibrils from $A \beta$, IAPP, or $\alpha$-synuclein}

For $A \beta 1-42$ fibrils, $A \beta 1-42$ (1 mg) was dissolved in $200 \mu \mathrm{l} 10 \mathrm{mM} \mathrm{NaOH}(5 \mathrm{mg} / \mathrm{ml})$. Aliquots $(100 \mu \mathrm{l})$ were diluted in $400 \mu \mathrm{l}$ PBS $1.25 \times$ (final concentration $1 \mathrm{mg}$ / $\mathrm{ml}$ ) and were incubated at $37^{\circ} \mathrm{C}$ for $72 \mathrm{~h}$.

For islet amyloid polypeptide (IAPP) fibrils, $1 \mathrm{mg}$ IAPP (Anaspec, reference 60,804) was dissolved in $200 \mu \mathrm{l}$ dimethylsulfoxide (DMSO) $50 \%$ ( $5 \mathrm{mg} / \mathrm{ml})$. Aliquots of $100 \mu \mathrm{l}$ were diluted in $400 \mu \mathrm{l}$ PBS $1.25 \times$. Samples were incubated at $37^{\circ} \mathrm{C}$ for $72 \mathrm{~h}$.

For $\alpha$-synuclein fibrils, $\alpha$-synuclein (Millipore, reference AG938) was provided lyophilized in Tris- $\mathrm{HCl}$ buffer, $\mathrm{pH}$ 7.4 , and $500 \mu \mathrm{g} \alpha$-synuclein were dissolved in $200 \mu \mathrm{l} \mathrm{H}_{2} \mathrm{O}$ MilliQ + $50 \mu \mathrm{l} 500 \mathrm{mM} \mathrm{NaCl}$ solution. Samples were incubated by shaking at $37^{\circ} \mathrm{C}$ for 7 days $(750 \mathrm{rpm})$.

After the incubation, samples were centrifuged at $17,000 \mathrm{~g}$ for $20 \mathrm{~min}$ at $4{ }^{\circ} \mathrm{C}$. The supernatants were discarded. Pellets of synuclein fibrils were washed twice with $200 \mu \mathrm{l}$ PBS and then resuspended in $100 \mu \mathrm{l}$ PBS, and the fibril sample concentration was determined using the Bradford test. 


\section{Binding assay by ELISA}

Wells of enzyme-linked immunosorbent assay (ELISA) plates were coated with $50 \mu \mathrm{l}$ protofibrils, LMW A $\beta$, or fibrils at $1 \mu \mathrm{g} / \mathrm{ml}$ in PBS. Plates were incubated overnight at $4{ }^{\circ} \mathrm{C}$. Antigen excess was eliminated, and wells were blocked with $200 \mu \mathrm{l} /$ well PBS-T (PBS + Tween 0.02\%)/ milk $5 \%$ for $2 \mathrm{~h}$ at room temperature. Wells were washed four times with $300 \mu \mathrm{l}$ PBS-T, and $50 \mu \mathrm{l}$ test antibody was added to wells after serial threefold dilution in PBS-T starting from a concentration of $25 \mu \mathrm{g} / \mathrm{ml}$. Plates were incubated for $1 \mathrm{~h}$ at room temperature and then washed four times with $300 \mu \mathrm{l} /$ well PBS-T. Secondary antibody (rabbit anti-mouse or goat anti-human) conjugated with horseradish peroxidase (HRP) diluted to $1 / 10000$ in PBS- $\mathrm{T}$ was added and incubated for $1 \mathrm{~h}$ at room temperature. Wells were then washed four times with $300 \mu \mathrm{l} \mathrm{PBS}-\mathrm{T}$, and $100 \mu \mathrm{l} /$ well of 3,3',5,5' -tetramethylbenzidine (TMB) was added and incubated for $10 \mathrm{~min}$. The reaction was stopped by the addition of $100 \mu$ stop solution. Plates were read to measure the optical density (OD) at $450 \mathrm{~nm}$. Dose-response curves with 12 concentrations in duplicate were performed to derive the EC50s.

\section{Surface plasma resonance (SPR) affinity determination}

Analysis was performed on a Biacore T100 with HBS-EP + (10 mM HEPES, $150 \mathrm{mM}$ sodium chloride, $3 \mathrm{mM}$ EDTA, and $0.005 \%$ P20) as the running buffer. A Series $\mathrm{S}$ Protein A sensor chip was used for the analysis. Antibodies were diluted to $5 \mu \mathrm{g} / \mathrm{ml}$ in HBS-EP+. Monomeric A $\beta 1-42$ peptide (SEC-purified) was diluted to $1000 \mathrm{nM}$ $(4.5 \mu \mathrm{g} / \mathrm{ml})$ in HBS-EP+ and then serially diluted twofold for a total of six concentrations. A $\beta 1-42$ protofibrils were diluted to $100 \mathrm{nM}(66 \mu \mathrm{g} / \mathrm{ml})$ in HBS-EP+ and then serially diluted twofold for a total of six concentrations. Antibodies were captured via Fc domain on the Protein A surface for $60 \mathrm{~s}$ at $10 \mu \mathrm{l} / \mathrm{min}$ and then the $A \beta$ peptide solution (monomeric or protofibrils) was injected over the surface for $180 \mathrm{~s}$ at $30 \mu \mathrm{l} / \mathrm{min}$ followed by a 360-s dissociation. The Protein A surface was regenerated with a 60 -s injection of $10 \mathrm{mM}$ glycine- $\mathrm{HCl}, \mathrm{pH} 1.7$. The resulting sensorgrams were double-referenced and fitted to a 1:1 binding model to determine $k_{a}, k_{d}$, and $K_{D}$.

\section{Characterization of binding to human AD brain sections Digoxigenin conjugation of primary human $m A$ s s}

To characterize binding patterns of human mAb SAR228810 in human tissues, the primary antibodies (SAR228810, isotype controls, and 3D6 mAbs) were conjugated with digoxigenin (dig). Briefly, DIG-NHS $(11,333,054,001$, Roche) at $2 \mathrm{mg} / \mathrm{ml}$ was diluted in DMSO. Then, $23.5 \mu \mathrm{l}(70 \mathrm{nmol})$ of this solution was added to $1 \mathrm{mg}$ antibodies in $1 \mathrm{ml}$ PBS ( $\mathrm{pH}$ 8.5). This mixed solution was incubated for $2 \mathrm{~h}$ under gently stirring at room temperature. The labeled protein was eluted in PBS through Sephadex G-25 columns $(11,418,165,001$ Roche). The initial titration of labeled protein was determined with Bradford reagent and measured by FloStar (Optimal). Samples with a concentration of labeled protein over $100 \mu \mathrm{g} / \mathrm{ml}$ were pooled and concentrated on an Amicon ultra-15 centrifugal filter system (UFC910008, Millipore). The SAR228810-dig concentration was $1.31 \mathrm{mg} / \mathrm{ml}$, hulgG4-dig isotype 0.73 $\mathrm{mg} / \mathrm{ml}$, and 3D6-dig $0.71 \mathrm{mg} / \mathrm{ml}$.

\section{Human brain tissue sections}

Formalin-fixed and paraffin-embedded (FFPE) human $\mathrm{AD}$ and controls cortices sections were from internal collection. The diagnosis of the cases was given based on clinical and hospital neuropathologist's findings, and by internal quality control of senile plaques and neurofibrillary tangles before usage. Two $\mathrm{AD}$ and two control donors were evaluated in this study.

\section{Immunohistochemistry (IHC) procedure}

FFPE sections were dewaxed by xylene and dehydrated with progressive ethanol (70\%, 95\%, and 100\%) until distilled water. A pretreatment was performed with $70 \%$ formic acid for $10 \mathrm{~min}$ and rinsed under running water for $5 \mathrm{~min}$ before the IHC procedure. IHC was performed using the Ventana Discovery XT automated System (Ventana Medical System, Inc.) with a standard protocol. All detection systems were manufactured by Ventana Medical System Inc. IHC optimal concentrations for each antibody were determined by individual pilot studies under the standard condition. The primary antibody $(10 \mu \mathrm{g} / \mathrm{ml}$ SAR228810-dig or IgG4 isotype control-dig, $5 \mu \mathrm{g} / \mathrm{ml}$ 3D6-dig) was incubated on tissue sections for 4 $\mathrm{h}$, and then $2 \mathrm{mg} / \mathrm{ml}$ secondary mAb (IgG1 murine anti-dig-biotin, B7405; Sigma) for $40 \mathrm{~min}$. The tertiary $\mathrm{mAb}$ used UltraMap ${ }^{\mathrm{Tw}}$ anti-mouse conjugated with either alkaline phosphatase or horseradish peroxidase incubated for $16 \mathrm{~min}$. Sections were revealed either by DAB (bright-field light microscope) or Fast red (fluorescence light microscope detection systems).

\section{Congo red dye (fibrillary plaque marker) protocol}

Dewaxed sections were stained with Congo red solution (Microscopy Congo red staining kit, 101,641; Merck) for $10 \mathrm{~min}$, rinsed in distilled water, and differentiated in $\mathrm{KOH}$ for $30 \mathrm{~s}$. After dehydration in $95 \%$ and $100 \%$ ethanol, the sections were cover-slipped using mounting media (Cytoseal 60, 8310-4; Richard-Allan Scientific Inc.).

\section{Analysis method}

Fast red and Congo red dye sections were analyzed by a fluorescence microscope (BX61; Olympus) and photographed by the cell $\mathrm{F}$ software system (Olympus). DAB-immunolabeled sections were examined by a 
bright-light microscope (Eclipse E400 4; Nikon) and imaged by a digital image acquisition system (NIS-Elements F 3.0; Nikon).

\section{Primary neuronal culture $\mathrm{OA} \beta 42$ toxicity assays}

Primary neuronal cultures were prepared from the brains of 16-day-old mouse (OF1, Charles River Laboratories, France) embryos by dissecting and then dissociating cerebral cortices. Cells were plated in Dulbecco's modified Eagle's medium (DMEM) supplemented with $\mathrm{N} 2$ and B27 at a cell density of $4 \times 10^{5}$ cells $/ \mathrm{ml}$ in poly-D-lysine-coated 96-well culture microplates.

On the day of experiment, the concentrated working solution of all antibodies and control isotypes was prepared as a $10 \times$ solution by diluting each stock solution to $1.5 \mathrm{mg} / \mathrm{ml}$ in DMEM. Lower tested concentrations were prepared by diluting the concentrated working solution in DMEM. Final concentrations of tested antibody within the culture wells were 150,50 , or $15 \mu \mathrm{g} / \mathrm{ml}$, corresponding to $1,0.33$, or $0.1 \mu \mathrm{M}$, respectively.

A $\beta 42$ oligomers (oA $\beta 42)$ were prepared as previously reported [33]. Briefly, human A 42 peptide (reference 64115; California Peptide Research Inc., USA) was first solubilized at $1 \mathrm{mM}$ in hexafluoroisopropanol (HFIP; Sigma H8508). The resulting solution was aliquoted in microcentrifuge tubes (VWR 20170-293), the HFIP was allowed to evaporate in a ventilated hood, and the resulting clear peptide film was dried under vacuum in a SpeedVac and stored desiccated at $-20^{\circ} \mathrm{C}$ under vacuum. On the day of experiment, the frozen $A \beta 42$ sample was resuspended at $5 \mathrm{mM}$ in DMSO (Sigma D2650). A $\beta 42$ oligomers were obtained by diluting the $5 \mathrm{mM} \mathrm{A} \beta 42$ working solution to $100 \mu \mathrm{M}$ in ice-cold cell culture medium and incubating for $1 \mathrm{~h}$ at room temperature. This oA $\beta 42$ preparation was added to the culture medium at a final concentration of $5 \mu \mathrm{M}$. After 6 days in vitro, primary neuronal cultures were pretreated with anti-A $\beta$ antibodies for $1 \mathrm{~h}$ in culture medium without B27. Then the neurons were incubated with oA $\beta 42(5 \mu \mathrm{M})$ for $48 \mathrm{~h}$. Control application of drug-free medium but supplemented with the corresponding DMSO concentration (i.e., $0.1 \%$, the same as for $\mathrm{oA} \beta 42$ treatment) was run in parallel to the application of the test substance.

\section{Quantification of caspase-3/7 enzymatic activity}

Following experimental treatment, caspase-Glo 3/7 Assay kit solution (Promega Corporation USA, G7790) was mixed to each well and incubated for $4 \mathrm{~h}$ at room temperature. After incubation, fluorescence in samples was quantified using a Spectramax Gemini plate reader. Fluorescence intensity is proportional to caspase-3/7 enzymatic activity.

\section{Quantification of neurite network}

Following experimental treatment, cell cultures were fixed with $4 \%$ formaldehyde solution (Merck, 100,496) and then permeabilized in PBS/0.2\% Triton X-100 for immunostaining. Permeabilized cells were incubated overnight at $4{ }^{\circ} \mathrm{C}$ with a primary antibody recognizing the neuronal protein marker microtubule-associated protein 2 (MAP2; Millipore AB5622) followed by an incubation with a secondary antibody corresponding to Alexa Fluor 594 coupled-anti-rabbit antibody (Molecular probes, A11012) for $1 \mathrm{~h}$ at room temperature. After an additional washing step, fixed cells were then incubated for $15 \mathrm{~min}$ with Hoechst 33342 (Molecular probes H3570) to stain for nuclei $(0.2 \mu \mathrm{g} / \mathrm{ml})$. Analysis of the neurite network was performed on MAP-2 immunostained and Hoechststained cells using automated high content image analysis (In Cell Analyzer 2200, GE Healthcare, UK). The measurement of the neurite area (expressed as $\mu \mathrm{m}^{2}$ ) was used as the neurite network index.

\section{In-vivo pharmacological studies with murine SAR255952 mAb \\ Animals}

Animal used were males from the APPSL transgenic line (expressing the 751 amino-acid variant of APP harboring the so-called "Swedish" (K670 N/M671 L) and "London" (V717F) mutations under a Thy1.2 promoter) as described in reference [34] and backcrossed to $\mathrm{C} 57 \mathrm{Bl} / 6$ mice, and age- and sex-matched littermate wild-type mice. Animals were bred and maintained in Charles River France facilities and supplied at the age of 2 months (weight ranging from $21 \mathrm{~g}$ to $26 \mathrm{~g}$ ) for pharmacological studies. Experiments were performed at Sanofi in an AAALAC-accredited facility in full compliance with the standards for the care and use of laboratory animals, according to French and European Community (Directive 2010/63/EU) legislation. All procedures were approved by the local Animal Ethics Committee (CEEA \#24) and the French Ministry for Research. Mice were housed individually in an enriched environment in a pathogen-free facility at a constant temperature of $22 \pm 2{ }^{\circ} \mathrm{C}$ and humidity $(50 \pm 10 \%)$ on a 12-h light/dark cycle with ad libitum access to food and water. Animals were randomized to the different groups. All analyses were performed with operators blinded to the treatment groups.

\section{Treatments}

Male APPSL mice ( $n=15$ per group) were treated once a week by intraperitoneal (i.p.) administration of antibodies at the following indicated doses dissolved in PBS under a volume of $10 \mathrm{ml} / \mathrm{kg}: 10 \mathrm{mg} / \mathrm{kg}$ (Ctl-IgG1); 1, 3, and $10 \mathrm{mg} /$ $\mathrm{kg}$ (SAR255952); and 3 and $10 \mathrm{mg} / \mathrm{kg}$ (3D6). All treatments started at the age of 2 months. Treatment duration was 20 weeks for the biochemical and histological readouts. For the electrophysiological studies, four groups of mice treated with Ctl-IgG1 $(10 \mathrm{mg} / \mathrm{kg}$ ), SAR255952 (3 or $10 \mathrm{mg} / \mathrm{kg})$, or 3D6 $(10 \mathrm{mg} / \mathrm{kg})$ and a group of wild-type controls were maintained on extended treatment up to 
the age of 9 to 10 months when they were individually processed for brain slice preparation and electrophysiological recordings. Mice were anesthetized by intravenous (i.v.) coadministration of xylazine $(2.7 \mathrm{mg} / \mathrm{kg})$ and ketamine $(87 \mathrm{mg} / \mathrm{kg})$ under a volume of $10 \mathrm{ml} / \mathrm{kg}$ and were decapitated. Brains were removed, and one hemi-brain was prepared for biochemical quantitative measurements and the other was used for immunohistochemistry. Due to spontaneous mortality in this transgenic strain, 9-12 mice survived until the end of the treatment period with no group bias. All mice were used for biochemical analysis and are reported as individual values, while immunohistochemistry analysis was performed on nine mice per treatment group.

\section{Biochemical analysis}

For biochemical quantitative measurements, the hemi-cortex was prepared for quantitative measurement of total $A \beta$ accumulation and the hemi hippocampus for mRNA preparation. For biochemical analysis of total $A \beta$ levels, the hemi-cortex was weighed and homogenized in 10 volumes $(w / v)$ in ice-cold buffer solution (composed of $0.32 \mathrm{M}$ sucrose, Tris- $\mathrm{HCl} 4 \mathrm{mM}, \mathrm{pH} 7.4$, and containing a cocktail of protease inhibitors (Complete ${ }^{\mathrm{mm}}$, Roche Diagnostics $\mathrm{GmbH}$, Manheim-Germany)). One milliliter of homogenate was then mixed with $2 \mathrm{ml}$ of a $9 \mathrm{M}$ guanidine hydrochloride (GH) solution in $50 \mathrm{mM}$ Tris- $\mathrm{HCl}, \mathrm{pH} 7.4$, and mixed by three 15-min bath sonications (total duration of the cycle 1 h), followed by centrifugation at $50,000 \mathrm{~g}$ at $4{ }^{\circ} \mathrm{C}$ for 120 $\mathrm{min}$. The supernatant was retrieved and called as guanidine extracts ("total A $\beta$ "). Samples were further diluted 1:1000 with ice-cold saline buffer containing $150 \mathrm{mM} \mathrm{NaCl}, 0.5 \%$ bovine serum albumin $(B S A ; w / v), 0.05 \%$ Tween $20(w / v)$, and $20 \mathrm{mM}$ Tris- $\mathrm{HCl}, \mathrm{pH}$ 7.6. $\mathrm{A} \beta$ standards (Bachem) were prepared with the same final GH concentration. For one experiment, Tris-soluble, membrane, and insoluble fractions were prepared by differential extraction following reported procedures [35]. The final pellet was solubilized in $50 \mathrm{mM}$ Tris-HCl, pH 7.4, $6 \mathrm{M} \mathrm{GH}$.

Immunoblot analysis using the APP antibody $22 \mathrm{C} 11$ indicated that SAR255952 did not affect brain APP levels (data not shown).

$A \beta$ quantification $A \beta$ peptides were detected by electrochemiluminescence assays using anti- $\mathrm{A} \beta$ antibodies and a Sector Imager 2400 Analyzer (Meso Scale Discovery, MSD, Gaithersburg, MD, USA) as previously described [34] with minor modifications. The 4G8 murine monoclonal antibody (Senetek PLC), which specifically recognizes an epitope within the 18-24 amino-acid region of $A \beta$, was ruthenylated with MSD Sulfo-TAG NHS ester, according to the supplier's instructions (MSD). It was thereafter used in conjunction with a 6E10-biotinylated murine monoclonal antibody (Senetek PLC), which binds to an epitope within the $2-11$ amino-acid region of $A \beta$. This assay can detect both $A \beta 40$ and $A \beta 42$ peptides and all shorter forms with a core region comprised between position 2 and 24 of $A \beta$, thereafter termed pan-A $\beta$. To specifically measure A 342 levels, $6 \mathrm{E} 10$ was replaced by a murine monoclonal antibody, 22F9, which binds to the C-terminus of $A \beta 42$ (with no cross-reaction with $A \beta 40$ ). The levels of $A \beta$ peptide were expressed as $\mu \mathrm{g} / \mathrm{g}$ of wet tissue weight. For quantification of the soluble and insoluble fraction, the $A \beta$ panel kit (MSD; reference K15200G) was used to quantify $A \beta 38, A \beta 40$, and $A \beta 42$ subspecies and values are reported normalized to the protein content of the initial homogenate.

Antibody quantification in body fluids ELISA assays with coated fibrillary $A \beta$ were used to dose serum and CSF levels of antibodies as described in the section above, using a calibration curve in parallel with recombinant SAR255952 or 3D6 antibodies.

RNA analysis Hemi-hippocampus from each mouse was placed in a round-bottomed 2-ml tube containing a stainless magnetic bead and $0.5 \mathrm{ml}$ of Applied Biosystems nucleic acid purification lysis solution $(1 \times)$. The tissue was homogenized using a Mixer Mill MM 300 (Retsch) during $2 \times 1.30 \mathrm{~min}$ at $20 \mathrm{~Hz}$. Total RNA was isolated using the 6100 PrepStation (Applied Biosystems), according to the manufacturer's instructions, including a DNase treatment (protocol Isolation of Total RNA from Plant and Animal Tissue). To assess the quality and concentration of the total RNA, $1 \mu \mathrm{l}$ was analyzed on an RNA LabChip (Agilent) using a 2100 Bioanalyser (Agilent Technologies).

For real-time polymerase chain reaction (PCR), $2 \mu \mathrm{g}$ total RNA from each mouse was reverse transcribed with oligo (dT)16 and random primers using a High-Capacity cDNA Archive Kit (Applied Biosystems), following the manufacturer recommendations. The final reverse-transcription reaction-included template was $100 \mu \mathrm{l}$. Samples were then incubated for $10 \mathrm{~min}$ at $25^{\circ} \mathrm{C}$, followed by $120 \mathrm{~min}$ at $37^{\circ} \mathrm{C}$, and then heated at $95^{\circ} \mathrm{C}$ to denature the enzymes and stop the reaction. For real-time PCR, cystatin F was amplified using commercial Taqman probes (Mm00438349_m1) and the housekeeping gene R.L37A was amplified using a Quantitech primer assay from Qiagen (QT00252266). PCR amplification was performed according to the manufacturer's instructions (Applied Biosystems) using an ABI Prism 7900 sequence detector.

\section{Histology}

Subsequent to immersion fixation in $4 \%$ formaldehyde, frozen hemi-brains were cut serially along the entire latero-medial axis into sagittal sections (Cryostat HM560, Microm). Randomly selected series of $30 \mu \mathrm{m}$-thick 
free-floating sections were used to perform $A \beta$ peptide and IgG1 immunohistochemistry, and respectively used to quantify cerebral $A \beta$ peptide deposition and to detect therapeutic antibody that enters cerebral tissue. After pretreatment with $80 \%$ formic acid for 3 min for $A \beta$ immunostaining only, sections were incubated at room temperature for $30 \mathrm{~min}$ in $0.3 \%$ hydrogen peroxide and finally in blocking buffer (TBS with $0.2 \%$ BSA, Sigma). They were incubated overnight at $4{ }^{\circ} \mathrm{C}$ with primary antibodies: biotinylated mouse monoclonal anti-A $\beta$ peptide antibody (human AB17-24 (4G8, reference 9240-10, Signet, dilution $1 / 200$ ) or biotinylated goat anti-mouse IgG1 antibody (reference 1070-08, SouthernBiotech, dilution 1/200). Sections were further incubated with peroxidase-coupled avidin complex (Vectastain ABC kit, Vector Laboratories, dilution 1/400) for $30 \mathrm{~min}$. Diaminobenzidine substrate was used for color development. Sections immunostained with IgG1 were counterstained using $0.2 \%$ Congo red solution in $\mathrm{NaCl}$-saturated $80 \%$ ethanol (Accustain amyloid stain Congo Red Kit, HT60, Sigma).

Image analysis For $A \beta$ immunostaining, images of the entire sections were acquired on an Olympus dotslide BX scanner and quantitatively analyzed on a computer-based workstation (Mercator system/Explora Nova using Dotslide software). Based on a thresholding procedure allowing for automatic detection of individually stained deposits within both hippocampal and cortical areas, the total detectable surface area $\left(\mu \mathrm{m}^{2}\right)$ over eight anatomical levels representative of the entire latero-medial axis of the hemi-brain was measured. For IgG1/Congo double-staining, qualitative image analysis was performed on an Olympus scanner using bright-field microscopy.

\section{Electrophysiology}

On each day of experimentation, a mouse from one of the five extended treatment groups in interleaved order was processed for brain slice preparation and ex-vivo recording of glutamatergic field potentials in the hippocampus following classical methods. Briefly, the mice were culled by cervical dislocation and the brain was quickly dissected out and cooled in artificial cerebrospinal fluid (ACSF: $124 \mathrm{mmol} / \mathrm{l} \mathrm{NaCl}, 3 \mathrm{mmol} / \mathrm{l} \mathrm{KCl}, 1.3$ $\mathrm{mmol} / \mathrm{l} \mathrm{MgSO}_{4}, 2 \mathrm{mmol} / \mathrm{l} \mathrm{CaCl}, 1.3 \mathrm{mmol} / \mathrm{l} \mathrm{NaH} \mathrm{PO}_{4}$, $26 \mathrm{mmol} / \mathrm{l} \mathrm{NaHCO}_{3}$ and $10 \mathrm{mmol} / \mathrm{l}$ glucose). Coronal slices ( $350 \mu \mathrm{m}$ thick) were cut with a vibratome (Integraslice 7550 PSDS, Campden Instruments) and placed in a submersion-type recording chamber (Warner RC-26G; volume $200 \mu \mathrm{l})$ through which warmed $\left(28-30^{\circ} \mathrm{C}\right)$ and gassed $\left(95 \% \mathrm{O}_{2} / 5 \% \mathrm{CO}_{2}\right)$ ACSF was continuously superfused at $3 \mathrm{ml} / \mathrm{min}$. The healthiness of hippocampal synaptic function was assessed by analyzing the excitatory pathway projecting from the CA3 to the CA1 area. Electrical stimulations $(0.1 \mathrm{~ms}$ in duration) were delivered through bipolar tungsten electrodes placed on the trajectory of the Schaeffer collaterals. Extracellular field excitatory postsynaptic potentials (EPSPs) were recorded in the CA1 stratum radiatum through low impedance glass micropipettes filled with ACSF. Recordings started with a baseline stabilization period for at least $1 \mathrm{~h}$ during which the size of the EPSPs elicited by supraliminal stimulations delivered every $30 \mathrm{~s}$ was monitored. Once stabilized, a sequence of 16 stimuli of graded intensity from $25 \mu \mathrm{A}$ to $400 \mu \mathrm{A}$ with a step of $25 \mu \mathrm{A}$ was delivered to each preparation. Stimulation/response curves were constructed by plotting the mean $( \pm$ standard error of the mean (SEM)) EPSP amplitudes against the stimulation intensities applied to the slice at each of the 16 predefined intensity levels.

\section{Two-photon in-vivo imaging}

One 8-month-old APPSL female mouse was anesthetized with an i.p. injection of ketamine $(100 \mathrm{mg} / \mathrm{kg})+$ xylazine $(10.0 \mathrm{mg} / \mathrm{kg})$. A cranial window over the right cortical hemisphere was surgically implanted as described previously [36]. Methoxy-X04, a widely used tracer of amyloid deposits [37], was injected i.p. $24 \mathrm{~h}$ before the first imaging session $(10 \mathrm{mg} / \mathrm{kg}, 5 \mathrm{mg} / \mathrm{ml}$ solution). Stacks of images were collected with the vertical step of $2 \mu \mathrm{m}$. The SAR255952 antibody labeled with a fluorescent dye (DyeLight-649, Cambridge UK) was injected i.v. $(20 \mathrm{mg} / \mathrm{kg}, 4.7 \mathrm{mg} / \mathrm{ml})$ during the first imaging session. Four additional imaging sessions were performed at $30 \mathrm{~min}, 24 \mathrm{~h}, 72 \mathrm{~h}$, and $144 \mathrm{~h}$ after the i.v. administration of the fluorescently labeled SAR255952.

In-vivo two-photon imaging was performed using the FluoView1000 MP system (Olympus Europa, Hamburg, Germany) equipped with a mode-locked Ti:Sapphire Mai-Tai DeepSee femtosecond laser (Spectra-Physics, Santa Clara, CA, USA) and a water immersion $25 \times$ objective XLPlan $\mathrm{N}$ with high numerical aperture $(\mathrm{NA}=$ 1.05) specially designed for in-vivo imaging (Olympus Europa, Hamburg, Germany). The laser wavelength of $800 \mathrm{~nm}$ was used for excitation of both Methoxy-X04 and DyeLight-649. Fluorescence was collected using a beam-splitter and two band-pass filters: $420-500 \mathrm{~nm}$ for Methoxy-X04 and 660-740 nm for DyeLight-649.

Vertical stacks of square images $\left(500 \times 500 \mu \mathrm{m}^{2}\right)$ were collected with the vertical step of $2 \mu \mathrm{m}$ (total imaged depth of stacks: $350-400 \mu \mathrm{m}$ ) at the temporal interval of $10-30 \mathrm{~min}$. Each imaging field was imaged repeatedly in every imaging session. Images were preprocessed for noise reduction using ImageJ/Fuji plugins (Median 3D and Gaussian Blur 3D). All detected plaques were visually verified at each time point, and only the plaques $>$ $20 \mu \mathrm{m}$ in diameter were analyzed. A custom-made MATLAB (Mathworks, Natick, MA, USA) routine was used to align the coordinates of the plaques imaged at 
the different time points. Regions of interest (ROI) were carefully drawn to include five parenchymal plaques, five perivascular amyloid deposits, five intravascular regions, and five parenchymal regions. ROIs included the parenchymal plaques located 30 to $90 \mu \mathrm{m}$ below the cortical surface. The ROI coordinates were stored, and measurement of fluorescence intensity in the antibody channel was performed for all ROIs in all subsequent image stacks.

\section{Induction of immunotolerance for testing of human antibodies in mice}

The anti-CD4 monoclonal antibody GK1.5 was produced from a hybridoma acquired from American Type Culture Collection, ATCC ${ }^{ø}$ TIB-207 $[38,39]$. For immunodepletion induction, 11- to 12-week-old APP751SL mice were treated at day 0 and day 2 by intraperitoneal injection of $150 \mu \mathrm{g}$ GK1.5 while a control group (i.e., non-immunotolerized mice) was administered with PBS. On day 4, blood was taken by retro orbital sampling on a heparin-lithium coated tube (microvette ${ }^{\oplus}$, Sarstedt AG, Germany). CD4+ T lymphocytes were quantified using FACS analysis on a FACSCantoll flow cytometer using standard protocols with CD45-FITC (clone 104 BD Pharmigen), CD3e-alexa Fluor 647 (clone 17A2, eBioscience), and CD4-PE (RM4-4 clone, BioLegend) antibodies. All GK1.5-treated animals displayed reduced CD4 as evidenced by a ratio of CD4+ lymphocytes/total CD3+ lymphocytes of $0.01 \pm 0.01$ in the treated group compared with $0.48 \pm 0.20$ in the untreated mice.

\section{Chronic treatments with human therapeutic antibodies}

SAR228810, SAR255952, and control Ctl-IgG1 antibodies were administered at $10 \mathrm{mg} / \mathrm{kg}$ (weekly i.p. for 19 weeks, initiated 2 days after the second GK1.5 administration) in immunotolerized male APPSL mice starting at 3 months of age ( $n=13-14$ per group). A control group of non-immunotolerized APPSL mice (i.e., not treated with GK1.5 antibody) was treated with Ctl-IgG1 and used as a control for the immunodepletion induction. Mice were culled at 7 months of age. Quantitative assessment of preventive activity against cerebral $A \beta$ peptide deposition was performed using histology and RNA analysis as described above (for each group, animal numbers are indicated in Table 4).

\section{In-vivo safety study}

To determine the potential toxicity of SAR255952, experiments were carried out in older transgenic APPSL female mice (12 to 13 months of age at initiation of dosing, $n=13$ to 16 per group at the start) which develop higher levels of amyloid plaques and congophilic angiopathy than males. Mice received PBS vehicle for the control group or SAR255952 at 10, 20, or $50 \mathrm{mg} / \mathrm{kg}$ i.v. administration by bolus injection (tail vein) once weekly for 9 weeks. A separate group of female mice $(n=13$ at initiation of dosing) received 3D6 (the positive control group) at $40 \mathrm{mg} / \mathrm{kg}$ i.v. administration by bolus injection (tail vein) once weekly for 9 weeks. Gender and age were selected to insure abundant parenchymal and vascular amyloid load and a high antibody dose was used to maximize potential for brain microhemorrhages as previously reported [40] and from an initial in-house study.

Various parameters were evaluated, including mortality, clinical signs, body and organ weights, food consumption, hematology, and clinical chemistry.

\section{Anatomic pathology}

Mice were anesthetized with isoflurane for subclavicular clinical pathology blood sampling and then euthanized by exsanguination from the abdominal aorta. Terminal body weight was obtained on the day of necropsy and the absolute and relative (organ to body) weights were determined. A thorough necropsy (including abdominal and thoracic cavities) was performed and macroscopic observations were recorded. A comprehensive list of tissues/organs were collected, preserved in 10\% neutral-buffered formalin, and then processed to paraffin blocks. Tissue blocks (except the brain, see below) from control and SAR255952 high-dose groups were sectioned, stained with hemalum, eosin and saffron (HES) according to standard protocols, and evaluated by light microscopy. For the brain, five equidistant samples through the entire organ were made to obtain a total of six coronal brain sections that were embedded anterior side down. For each brain, two coronal brain sections were embedded per block resulting in the preparation of three paraffin blocks per brain. All brain blocks from all groups were sectioned. The three brain blocks per animal were stained with HES and with Perl's, resulting in six HES-stained and six Perl's-stained coronal brain sections per mouse. In the control, SAR255952 high-dose, and 3D6 groups, six additional sections at $50-\mu \mathrm{m}$ intervals per block were performed and stained with Perl's, resulting in 36 additional coronal brain Perl's-stained sections per mouse. All stained brain sections were examined by light microscopy.

\section{Expression of results and statistical analysis}

Mean \pm SEM in-vitro EC50 values for antibody binding affinities were calculated by nonlinear regression according to a classical four-parameter logistic model (GraphPad Prism 7.02).

For other biochemical data, results are expressed as mean \pm SEM (Tables 1-3). For quantitative PCR (qPCR), cycle threshold $(\mathrm{Ct})$ values were converted in relative quantity (RQ) using the equation: RQ equal to $2(\mathrm{Ct}(\mathrm{L} 37 \mathrm{a})-$ $\mathrm{Ct}($ CystatinF)) for each hippocampus sample divided by 2(Ct (L37a) - Ct(CystatinF)) for a referent total brain sample. 
Table 1 In-vitro binding characteristics of SAR2559952, humanized SAR228810, and comparators

\begin{tabular}{|c|c|c|c|c|c|c|}
\hline \multirow[t]{2}{*}{ Mouse IgG } & \multicolumn{2}{|l|}{ ELISA A $\beta$} & \multicolumn{4}{|c|}{ ELISA aggregated proteins } \\
\hline & \multicolumn{2}{|l|}{$\mathrm{EC} 50 \mathrm{ng} / \mathrm{ml}$} & \multicolumn{4}{|l|}{$\mathrm{EC} 50 \mathrm{ng} / \mathrm{ml}$} \\
\hline Mean EC50 & Protofibril (soluble) & LMW/monomer & \multicolumn{2}{|l|}{ Fibril/aggregates } & IAPP fibrils & Synuclein fibrils \\
\hline SAR255952 & $36 \pm 5.5$ & $3751 \pm 130$ & \multicolumn{2}{|l|}{$68 \pm 15$} & NB up to $100 \mu \mathrm{g} / \mathrm{ml}$ & NB up to $100 \mu \mathrm{g} / \mathrm{ml}$ \\
\hline 3D6 & $61 \pm 4.4$ & $86 \pm 6$ & \multicolumn{2}{|l|}{$45 \pm 17$} & NB up to $100 \mu \mathrm{g} / \mathrm{ml}$ & NB up to $100 \mu \mathrm{g} / \mathrm{ml}$ \\
\hline \multirow[t]{3}{*}{ Human lgG } & \multicolumn{2}{|l|}{ ELISA AB } & \multicolumn{2}{|c|}{ ELISA aggregated proteins } & \multicolumn{2}{|l|}{ SPR } \\
\hline & \multicolumn{2}{|l|}{$\mathrm{EC} 50 \mathrm{ng} / \mathrm{ml}$} & \multicolumn{2}{|l|}{$\mathrm{EC} 50 \mathrm{ng} / \mathrm{ml}$} & \multicolumn{2}{|l|}{$K_{d}(M)$} \\
\hline & Protofibrils (soluble) & LMW/monomer & A $\beta$ fibrils IAPP fibrils & Synuclein fibrils & $A \beta$ monomer & $A \beta$ protofibrils (soluble) \\
\hline SAR228810 & $37 \pm 2$ & $14,403 \pm 3403$ & $16.7 \pm 3.4 \quad N B$ & NB & NB up to $1000 \mathrm{nM}$ & $4.3 \pm 5 \times 10^{-10}$ \\
\hline 3D6 human IgG & $32 \pm 2$ & NA & $7.7 \pm 2.2 \quad \mathrm{NA}$ & NA & $1.7 \pm 1 \times 10^{-8}$ & $<10^{-10}$ \\
\hline Gantenerumab & $26 \pm 8$ & NA & $19.9 \pm 4.7 \quad \mathrm{NA}$ & NA & $3.4 \pm 3 \times 10^{-5}$ & $8 \pm 3 \times 10^{-10}$ \\
\hline BAN-2401 & $21.3 \pm 9$ & NA & $15.5 \pm 5.1 \quad \mathrm{NA}$ & NA & $8.7 \pm 4 \times 10^{-6}$ & $<10^{-10}$ \\
\hline
\end{tabular}

Binding experiments performed three to five times, mean \pm SEM EC50 values are presented

$A \beta$ amyloid $\beta, E L I S A$ enzyme-linked immunosorbent assay, IAPP islet amyloid polypeptide, $L M W$ low molecular weight, NA not available, NB no binding,

For immunohistochemistry, the average of individual measurements of total surface occupied by $A \beta$ immunostaining over eight sections was used to calculate group means. Normality and homogeneity of variances hypotheses were tested with Shapiro-Wilks and Levene tests, respectively. Although the A $\beta 42$ was not normally distributed in the 3D6 $(10 \mathrm{mg} / \mathrm{kg})$ group due to an extreme value, parametric analyses were used. Data were assessed with one-way analysis of variance (ANOVA), followed by post-hoc two-sided Dunnett's test versus control. The Ctl-IgG1 group was first compared with the SAR25 5952-treated groups and then to the 3D6-treated groups. For cystatin F mRNA expression, a nonparametric analysis was used since, in most of the cases, the hypotheses were not fulfilled. mRNA data were assessed with a nonparametric Kruskal-Wallis test, followed by a post-hoc two-sided Kruskal-Wallis multiple comparisons test versus control. The statistical analyses were performed using the SAS system release 8.2 for SUN4 via Everstat 5.0 software. A probability value of $p<0.05$ was considered significant.

The amplitudes of the EPSPs were subjected to two-way ANOVA with stimulation intensity as the repeated factor. Post-hoc analysis of effects at each level of stimulation intensity was performed by Dunnett's test comparing the Ctl-IgG1 group with each dose of SAR255952. Results are expressed as mean values \pm SEM in the figures.

\section{Results}

SAR255952 is a mutant aglycosylated version of $A \beta$ protofibril-specific murine antibody 13C3 ([29]; WO2009/ 065054) obtained by mutation of the glycosylation site in the Fc domain (N297A). SAR228810 is the corresponding humanized version designed with a human mutated IgG4Fc domain. As designed, both antibodies display reduced binding to $\mathrm{Fc} \gamma \mathrm{R}$ and complement $\mathrm{C} 1 \mathrm{q}$ (Additional file 1: Table S1), indicating drastically reduced effector functions. In the present study, we first confirmed by ELISA that SAR255952 maintained a higher affinity for soluble HMW $\mathrm{A} \beta$ protofibrils (size exclusion chromatography purified) compared with LMW A $\beta$ complexes (including monomers) with EC50 values of $36 \pm 5.5 \mathrm{ng} / \mathrm{ml}(n=6)$ and $3751 \pm 130$ $\mathrm{ng} / \mathrm{ml}(\mathrm{n}=6)$, respectively, while the pan $\mathrm{A} \beta$-conformer antibody 3D6 (murine bapineuzumab) displayed similar affinities for both $A \beta$ conformations (Fig. 1 and Table 1). We further demonstrated that SAR255952 was specific for $A \beta$ fibrils (EC50 value of $68 \pm 15 \mathrm{ng} / \mathrm{ml}$ ) with no binding to IAPP or $\alpha$-synuclein fibrils (Table 1 ). The $A \beta$ peptide conformation-restricted binding was further confirmed by $\mathrm{A} \beta$ peptide fragment scan analysis that failed to detect high affinity binding of SAR255952 to any linear 12 amino-acid peptide from the $A \beta$ sequence (data not shown).

The humanized version SAR228810 displayed a similar specificity for $A \beta$ protofibrils versus monomeric $A \beta$ as confirmed by ELISA, with EC50 values of $37 \pm 2 \mathrm{ng} / \mathrm{ml}$ ( $n=4$ separate experiments, in quadruplicate each) versus $14,403 \pm 3403 \mathrm{ng} / \mathrm{ml}(\mathrm{n}=6)$, respectively (Table 1$)$. Using surface plasma resonance (SPR), SAR228810 displayed high affinity for $\mathrm{A} \beta$ protofibrils $\left(\mathrm{K}_{\mathrm{D}}=4.3 \pm 5 \times 10^{-10} \mathrm{M}\right)$ and no binding for monomeric $A \beta$ up to $1000 \mathrm{nM}$, while 3D6-human chimera had high binding affinity for both $A \beta$ conformers $\left(K_{D}<10^{-10} M\right.$ (resolution limit of this technique) for $A \beta$ protofibrils and $K_{D}=1.7 \pm 1 \times 10^{-8} \mathrm{M}$ for monomeric A $\beta$ (Table 1$)$ ). Again, SAR228810 was specific for $A \beta$ aggregated forms versus IAPP or synuclein aggregates. Two additional clinical anti-protofibrillar $A \beta$ antibodies, gantenerumab and BAN2401, also displayed high affinity for fibrillar and protofibrillar $A \beta$ but had residual binding to monomeric $\mathrm{A} \beta\left(\mathrm{K}_{\mathrm{D}}=3.4 \times 10^{-5} \mathrm{M}\right.$ and $8.7 \times 10^{-6} \mathrm{M}$, respectively). 


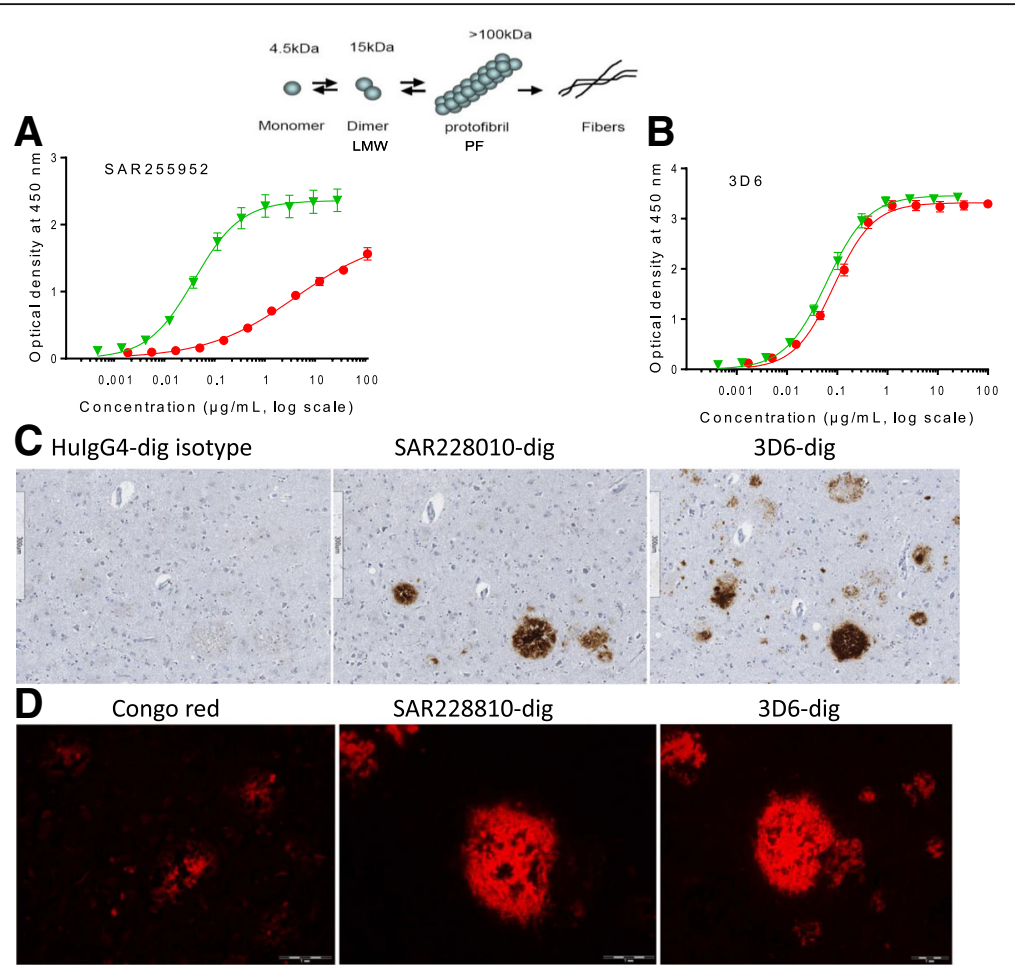

Fig. 1 Specificity of SAR255952 and humanized SAR228810 for soluble Aß protofibrils and fibrillar forms but not low molecular weight A or monomers. Synthetic $A \beta_{42}$ was allowed to aggregate in aqueous saline buffer. Soluble, low molecular weight (LMW) A complexes and $A \beta$ monomers (red circles) were separated from higher order fibrillar aggregates (green triangles) by size exclusion chromatography. In ELISA apparent affinity determinations, SAR255952 demonstrates high affinity and strong preference for protofibrillar A $\beta$ versus monomeric $A \beta(\mathbf{a})$, unlike 3D6 (bapineuzumab) that equally binds to both $A \beta$ conformations (b). Similar data were obtained with the humanized version SAR228810. In human AD cortical sections, SAR228810 specifically binds to compact amyloid deposits while 3D6, in addition, detects a large number of diffuse deposits (chromogenic stain panel c). This was confirmed with fluorescence labeling with SAR228810 binding to a large area around Congo red-positive core plaques, while 3D6 labeled in addition non-Congo red-positive deposits (diffuse deposits). Symbols and error bars indicate mean \pm SEM from ELISA readings. Scale bars represent $300 \mu \mathrm{m}$ in panel $\mathbf{c}$ and $1 \mu \mathrm{m}$ in panel $\mathbf{d}$

\section{Characterization of SAR228810 binding in human brain sections}

The validation of SAR228810-dig mAb was carried out in human $\mathrm{AD}$ and control cortices. Using a chromogenic method, SAR228010-dig was shown to specifically bind $\mathrm{A} \beta$ deposits in the human $\mathrm{AD}$ cortex (Fig. 1c), without any binding in the normal brain (not shown). In adjacent AD brain sections, 3D6-dig labeled a higher number of $\mathrm{A} \beta$ deposits with various morphological patterns in comparison with SAR228010-dig. As a control, the huIgG4-dig isotype did not show any labeling (Fig. 1c).

To characterize the binding difference between the two antibodies, we compared the SAR228010-dig and 3D6-dig labeling pattern with Congo red staining using an immunofluorescence method in adjacent brain sections. Congo red dye is known to stain only fibrillar amyloid in parenchymal plaques and in angiopathy (vessel wall). SAR228810-dig mAb mainly labeled focal $A \beta$ deposits that were also stained by Congo red dye, as well as the peri-core area (Fig. 1d). In comparison, 3D6-dig mAb was shown to immunostain not only the Congo red-positive deposits and peri-core area but also a high number of parenchymal diffuse deposits (Fig. 1d). Moreover, no binding was found in human aging healthy brain structures (frontal cortex, calcarine, hippocampus, substantia nigra, olive nucleus, raphe nucleus, cerebellum, and corpus callosum), nor in another 38 types of human tissue that compose the US Food and Drug Administration (FDA) recommended panel, nor in monkey and mouse cross-reactivity studies (data not shown).

In agreement with the biochemical binding selectivity for fibrillar and protofibrillar $\mathrm{A} \beta$, in human $\mathrm{AD}$ cortices, SAR228810 specifically immunolabeled Congo red-positive amyloid deposits in angiopathy, peri-vascular deposits, and parenchymal plaques without any labeling in other human organs. In comparison, 3D6 labeled a large number of diffuse $A \beta$ deposits in addition.

\section{Protection against oA 342 toxicity in primary neuronal cultures}

The potential neuroprotective activity of SAR228810 and SAR255952 was evaluated in an in-vitro model of oA $\beta 42$ 
neurotoxicity in mouse primary neuronal cultures quantifying neurite network and caspase 3/7 enzymatic activity. Co-treatment of oA 442 with SAR228810 or SAR255952 inhibited an oA 342 -induced decrease in the neurite network as observed on cell images of MAP2 staining (Fig. 2a). Based on quantitative automated image analysis, SAR22 8810 and SAR255952 prevented an oAß42-induced decrease in the neurite network in a concentration-dependent manner, with a maximal protective effect of 80 and 103\% at the highest concentration tested $(150 \mu \mathrm{g} / \mathrm{ml}$, i.e., $1 \mu \mathrm{M})$, respectively (Fig. 2b). SAR228810 and SAR255952 also inhibited the oA $\beta 42$-induced increase in caspase-3/7 enzymatic activity in a concentration-dependent manner with a maximal protective effect of 93 and $94 \%$ at the highest concentration tested $(150 \mu \mathrm{g} / \mathrm{ml})$, respectively (Fig. $2 \mathrm{c}$ ).

In comparison with other clinical anti-A $\beta$ antibodies, SAR228810 had a similar neuroprotective activity when measuring the neurite network compared with gantenerumab and BAN240,1 but was significantly more potent on the caspase-3/7 readout (the latter two being almost inactive) (Table 2). This might suggest that the o $\beta 42$ preparation used contained several toxic entities affecting either neurite integrity or caspase activation and that, while
SAR228810 can neutralize both, the other two antibodies can neutralize only the former. This adds to the significant differences in binding to the different $A \beta$ conformers observed between the three mAbs. In the absence of oA $\beta 42$, no significant effect was observed between control, SAR228810, SAR255952, BAN-2401, or gantenerumab tested alone (data not shown). The isotype control hIgG4 (for SAR228810) or the isotype control mIgG1 and hIgG1 (for SAR255952 and BAN-2401/gantenerumab, respectively) displayed no neuroprotective activity (data not shown). Under these experimental conditions, 3D6-bapi neuzumab led to formation of large precipitates with oA $\beta$, preventing evaluation of its neuroprotective activity.

\section{Prevention of amyloid plaque development in vivo by murine SAR255952}

We next evaluated the efficacy of chronic treatment with murine SAR255952 to prevent brain A $\beta$ deposition in APPSL transgenic mice in comparison with a negative control IgG1, Ctl-IgG1, that recognizes a non-mammalian antigen, and to a reference mouse 3D6, the mouse version of bapineuzumab. Dosing (weekly,

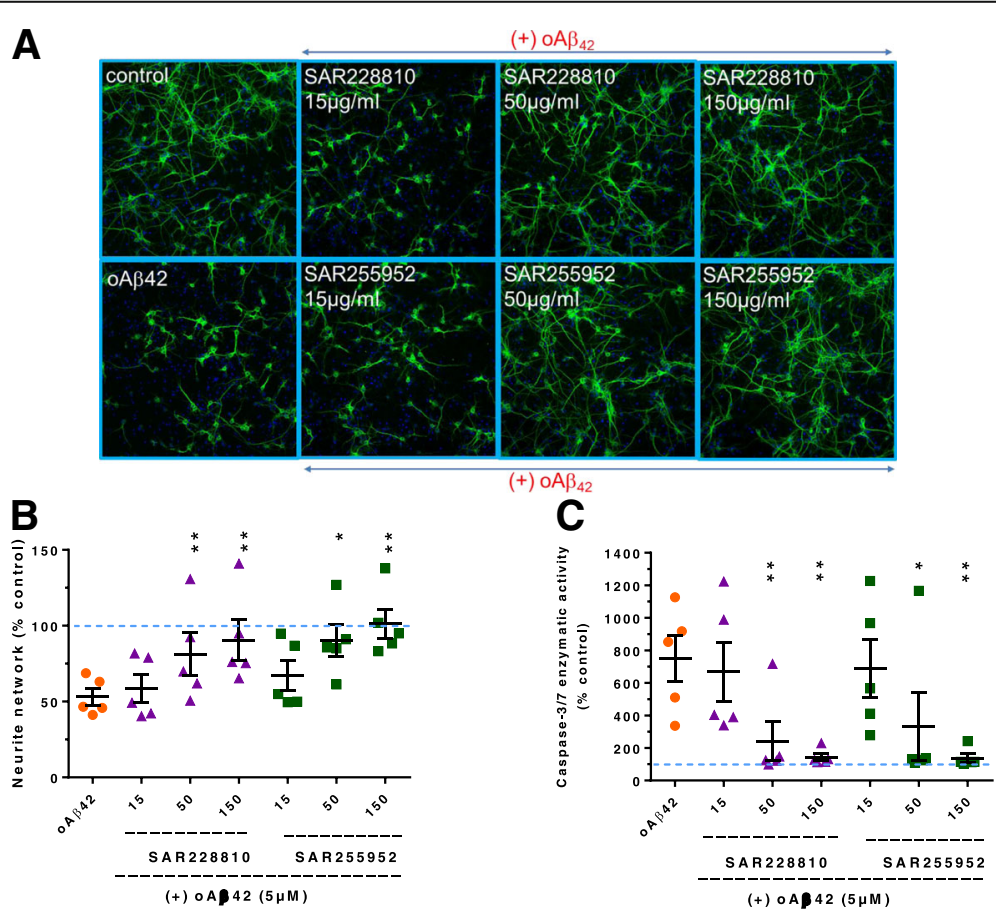

Fig. 2 SAR255952 and SAR228810 protect neurons from A oligomer neurotoxicity in vitro. Concentration-response effects of SAR228810 and SAR255952 on the loss of neurite network and the increase in caspase-3/7 enzymatic activity induced by oA 42 in mouse primary neuronal cultures. a Cell images of MAP2 immunostaining in mouse primary neuronal cultures following a 48-h treatment with oligomeric amyloid $\beta$ (OAB) 42 with or without anti-amyloid antibodies. b Quantification of the effects of anti-amyloid antibodies on the neurite network as measured by automated image analysis of MAP2 staining. $\mathbf{c}$ Effects of anti-amyloid antibodies on cell viability as measured by caspase-3/7 enzymatic activity. ${ }^{*} p$ $=0.0023 ;{ }^{* *} p<0.0001 ; p=0.0062 ; p=0.0352$, by two-tailed Dunnett's test with respect to oA $\beta 42$. Horizontal axis represents concentration of respective $\mathrm{mAbs}$ in $\mu \mathrm{g} / \mathrm{ml}$. Horizontal black lines and error bars denote mean \pm SEM data. Data are expressed as percentage of control group from five independent experiments. Dotted lines correspond to control values without oAß42 (100\%) 
Table 2 Comparison of SAR228810 with other clinical anti-amyloid antibodies in neuroprotection assay

\begin{tabular}{|c|c|c|c|c|c|c|c|}
\hline \multirow{2}{*}{$\begin{array}{l}\% \text { control response } \\
\text { (no oA } 442 \text { ) }\end{array}$} & \multirow{2}{*}{$\begin{array}{l}O A \beta 42 \\
5 \mu \mathrm{M}\end{array}$} & \multicolumn{2}{|c|}{$\mathrm{OA} 342+\mathrm{SAR} 228810$} & \multicolumn{2}{|c|}{ oA $\beta 42$ + gantenerumab } & \multicolumn{2}{|c|}{$\mathrm{OAB42}+\mathrm{BAN}-2401$} \\
\hline & & $50 \mu \mathrm{g} / \mathrm{ml}$ & $150 \mu \mathrm{g} / \mathrm{ml}$ & $50 \mu \mathrm{g} / \mathrm{ml}$ & $150 \mu \mathrm{g} / \mathrm{ml}$ & $50 \mu \mathrm{g} / \mathrm{ml}$ & $150 \mu \mathrm{g} / \mathrm{ml}$ \\
\hline \multirow{2}{*}{$\begin{array}{l}\text { Neurite network } \\
\text { (MAP2) }\end{array}$} & \multirow[t]{2}{*}{$49.84 \pm 10.29$} & $86.17 \pm 10.25$ & $96.49 \pm 0.86$ & $70.57 \pm 1.66$ & $82.27 \pm 6.70$ & $79.34 \pm 0.70$ & $86.78 \pm 2.75$ \\
\hline & & $p<0.0001$ & $p<0.0001$ & $p=0.0022$ & $p<0.0001$ & $p=0.0059$ & $p<0.0001$ \\
\hline \multirow[t]{2}{*}{ Caspase 3/7 activity } & \multirow[t]{2}{*}{$291.47 \pm 48.73$} & $190.84 \pm 39.15$ & $103.42 \pm 10.36$ & $388.89 \pm 150.02$ & $360.38 \pm 123.53$ & $428.48 \pm 136.51$ & $355.14 \pm 124.57$ \\
\hline & & $p=0.0001$ & $p<0.0001$ & NS & NS $(p=0.2562)$ & $\mathrm{NS}(p=0.8675)$ & NS $(p=0.9995)$ \\
\hline
\end{tabular}

Control response without $\mathrm{OA} \beta 42=100 \%$; data are expressed as medians \pm median absolute deviation (MAD); $n=3-7$

$P$ values were obtained with a Dunnett's test versus oA $\beta 42$ after a one-way ANOVA on rank-transformed data

NS not significant, $O A \beta$ oligomeric amyloid $\beta$

i.p.) was initiated at 2 months of age close to the onset of amyloid deposition in this transgenic line.

A 4-month chronic treatment with SAR255952 (10 mg/ $\mathrm{kg}$ ) significantly decreased guanidine-solubilized pan-A $\beta$ levels $(-41 \%$ at $10 \mathrm{mg} / \mathrm{kg}, \quad p<0.01)$ versus Ctl-IgG1treated controls in the cortex while a nonsignificant trend was observed at $3 \mathrm{mg} / \mathrm{kg}(-25 \%)$ and no effect at $1 \mathrm{mg} / \mathrm{kg}$ $(+6 \%)$ (Table 3). In comparison, the reference 3D6 (10 $\mathrm{mg} / \mathrm{kg})$ decreased cortical pan-A $\beta$ levels $(-43 \%, p<0.05)$ while the dose of $3 \mathrm{mg} / \mathrm{kg}$ was inactive (Table 3 ).

SAR255952 treatment did not significantly decrease guanidine-solubilized cortical A $\beta 42$ levels $(+16 \%$, not significant at $1 \mathrm{mg} / \mathrm{kg} ;-13 \%$, not significant at $3 \mathrm{mg} / \mathrm{kg}$; $-31 \%$, not significant at $10 \mathrm{mg} / \mathrm{kg}$ ) versus Ctl-IgG1-treated controls (Table 3), nor did the reference 3D6 $(+11 \%$, not significant at $3 \mathrm{mg} / \mathrm{kg} ;-35 \%$, not significant at $10 \mathrm{mg} / \mathrm{kg}$ ). In an independent in-vivo study comparing Ctr-IgG1 and SAR255952 at the dose of $10 \mathrm{mg} / \mathrm{kg}$ in a similar 4-month treatment, differential extraction of soluble, membrane, and insoluble fractions demonstrated that SAR255952 led to a comparable decrease in soluble and insoluble fractions of all three $A \beta$ subspecies ( $A \beta 38, A \beta 40$, and $A \beta 42)$ (Additional file 1: Table S2). The membrane fraction interferes in the MSD assay and could not be quantified.

Brain $A \beta$ peptide deposition was further analyzed by immunohistochemistry. All 6-month-old Ctl-IgG1treated APPSL transgenic mice had developed a reproducible and moderate density of small and large extracellular $A \beta$ deposits over the entire latero-medial axis of both cortical (Table 3, Fig. 3a) and hippocampal brain areas (Table 3).

In SAR255952-treated mice, quantitative analysis evidenced a dose-dependent decrease in the total surface occupied by $\mathrm{A} \beta$ immunostaining in extracellular deposits in both cortical and hippocampal brain areas. The decrease in extracellular $\mathrm{A} \beta$ peptide deposition in the cortex was $-78 \%(p<0.0001)$ at $10 \mathrm{mg} / \mathrm{kg},-51 \%(p=0.013)$ at $3 \mathrm{mg} / \mathrm{kg}$, and $11 \%$ (not significant) at $1 \mathrm{mg} / \mathrm{kg}$ compared with the Ctl-IgG1-treated control group (Table 3, Fig. 3a). In the hippocampus, the decrease was $-80 \%(p$ $<0.0001)$ at $10 \mathrm{mg} / \mathrm{kg},-59 \%(p=0.012)$ at $3 \mathrm{mg} / \mathrm{kg}$, and $35 \%$ (not significant) at $1 \mathrm{mg} / \mathrm{kg}$ (Table 3). 3D6 treatment at the dose of $10 \mathrm{mg} / \mathrm{kg}$ also led to a marked decrease $(-60 \%, p=0.003)$ in extracellular $\mathrm{A} \beta$ peptide deposition in the cortex but was inactive at $3 \mathrm{mg} / \mathrm{kg}$ $(+1 \%$, not significant, Fig. 3a). In the hippocampus, the decreases were $-41 \%(p=0.012)$ at $10 \mathrm{mg} / \mathrm{kg}$ and $-25 \%$ (not significant, $p=0.089$ ) at $3 \mathrm{mg} / \mathrm{kg}$ (Table 2).

From previous characterization of amyloid transgenic models, we selected cystatin F mRNA levels in the hippocampus as a sensitive marker of brain inflammation. SAR255952 treatment significantly decreased cystatin $\mathrm{F}$ mRNA levels by $-78 \%$ at $10 \mathrm{mg} / \mathrm{kg}(p<0.0001)$ and $-47 \%$ at $3 \mathrm{mg} / \mathrm{kg}(p<0.05)$ versus Ctl-IgG1-treated controls while, at $1 \mathrm{mg} / \mathrm{kg}$, SAR255952 had no significant effect (Table 3, Fig. 3c). Similarly, 3D6 at the dose of $10 \mathrm{mg} / \mathrm{kg}$ significantly decreased cystatin $\mathrm{F}$ mRNA levels $(-51 \%, p<0.05)$ while the dose of $3 \mathrm{mg} / \mathrm{kg}$ had no significant effect $(+12 \%$, not significant) (Table 3, Fig. 3c). In addition, by immunohistochemistry, the frequency of Iba1-positive activated microglia cells as well as GFAP-positive astrocytes in clusters around $A \beta$ deposits were massively decreased in the SAR255952 high dose-treated animals (data not shown).

Additional characterization by immunohistochemistry revealed that SAR255952 treatment led to a decrease in deposit-associated dystrophic neurites as evaluated with APP immunohistochemistry with antibody 22C11 (data not shown), commensurate with amyloid deposit lowering. Tau phosphorylation levels (AT8 immunoreactivity) at the end of treatment were too limited to be able to document a treatment effect.

These data indicated that a protofibrillar $A \beta$-specific antibody with much reduced effector functions was at least as effective as a pan- $A \beta$ antibody with full effector function at preventing $A \beta$ peptide deposition and related inflammation.

\section{Lack of effect of SAR255952 on plasma A $\beta$ levels}

Treatment with a range of different anti-A $\beta$ antibodies has been reported to lead to a large increase in plasma $A \beta$ levels, likely due to binding and stabilization of $A \beta$ in the plasma which is otherwise very quickly degraded partly by the liver [41]. At 7 days following the last dose 
Table 3 Antibody dose-dependent prevention of amyloid accumulation and inflammation in APPSL transgenic mice

\begin{tabular}{|c|c|c|c|c|c|c|}
\hline \multirow{2}{*}{$\frac{\text { Treated groups }}{\text { Dose }(\mathrm{mg} / \mathrm{kg})}$} & \multirow{2}{*}{$\frac{\text { Ctrl-IgG1 }}{10}$} & \multicolumn{3}{|l|}{ SAR255952 } & \multicolumn{2}{|l|}{$3 \mathrm{D} 6$} \\
\hline & & 1 & 3 & 10 & 3 & 10 \\
\hline \multicolumn{7}{|l|}{ Biochemical cortical A $\beta$} \\
\hline Pan-A $\beta \mu \mathrm{g} / \mathrm{g}$ tissue & $23.7 \pm 1.7$ & $25.1 \pm 1.8$ & $17.8 \pm 1.7$ & $14.0 \pm 1.4$ & $24.3 \pm 2.3$ & $13.5 \pm 3.4$ \\
\hline \multirow[t]{2}{*}{$\%$ reduction vs. Ctrl-lgG1 } & & $+6 \%$ & $-25 \%$ & $-41 \%$ & $+3 \%$ & $-43 \%$ \\
\hline & & NS & NS & $p<0.05$ & NS & $p<0.001$ \\
\hline A $342 \mu \mathrm{g} / \mathrm{g}$ tissue & $7.62 \pm 0.58$ & $8.86 \pm 0.74$ & $6.62 \pm 0.68$ & $5.28 \pm 0.77$ & $8.49 \pm 0.84$ & $4.92 \pm 1.65$ \\
\hline \multirow[t]{2}{*}{$\%$ reduction vs. Ctrl-lgG1 } & & $+16 \%$ & $-13 \%$ & $-31 \%$ & $+11 \%$ & $-35 \%$ \\
\hline & & NS & NS & NS & NS & NS \\
\hline Cystatin F mRNA hippocampus & $4.47 \pm 0.35$ & $4.27 \pm 0.35$ & $2.35 \pm 0.29$ & $0.99 \pm 0.07$ & $4.99 \pm 0.37$ & $2.19 \pm 0.49$ \\
\hline \multirow[t]{2}{*}{$\%$ reduction vs. Ctrl-lgG1 } & & $-4 \%$ & $-47 \%$ & $-78 \%$ & $+12 \%$ & $-51 \%$ \\
\hline & & NS & $p<0.05$ & $p<0.001$ & NS & $p<0.05$ \\
\hline \multicolumn{7}{|l|}{$A \beta$ immunohistochemistry } \\
\hline Total area cortex $\left(\mu \mathrm{m}^{2}\right)$ & 382,388 & 339,950 & 188,729 & 83,495 & 387,344 & 151,764 \\
\hline SEM & 29,945 & 44,091 & 19,154 & 14,776 & 53,255 & 31,968 \\
\hline \multirow[t]{2}{*}{$\%$ reduction vs. Ctrl-IgG1 } & & $-11 \%$ & $-51 \%$ & $-78 \%$ & $+1 \%$ & $-60 \%$ \\
\hline & & NS & $p=0.013$ & $p<0.0001$ & NS & $p=0.003$ \\
\hline Total area hippocampus $\left(\mu m^{2}\right)$ & 103,417 & 66,849 & 42,794 & 20,646 & 77,838 & 60,972 \\
\hline SEM & 11,020 & 13,435 & 4546 & 4329 & 9786 & 8192 \\
\hline \multirow[t]{2}{*}{ \% reduction vs. Ctrl-lgG1 } & & $-35 \%$ & $-59 \%$ & $-80 \%$ & $-25 \%$ & $-41 \%$ \\
\hline & & NS & $p=0.0123$ & $p<0.0001$ & NS & $p=0.0116$ \\
\hline Plasma Aß40 pg/ml & $175 \pm 31$ & $198 \pm 20$ & $201 \pm 34$ & $211 \pm 27$ & $680 \pm 130$ & $999 \pm 142$ \\
\hline
\end{tabular}

For the different parameters, values represent mean \pm standard error of the mean (SEM) unless indicated otherwise $A \beta$ amyloid $\beta, N S$ not significant

in the chronic treatment study described above, we confirmed that 3D6 treatments leads to a large increase in plasma $A \beta 40$ levels (plasma $A \beta 42$ could not be detected with the sensitivity of our assay), while SAR255952 did not affect A $\beta 40$ levels (Table 3, Additional file 2: Figure $\mathrm{S} 1$ ). At the dose of $10 \mathrm{mg} / \mathrm{kg}$ in these samples, SAR225952 levels $(149.6 \pm 7.9 \mu \mathrm{g} / \mathrm{ml})$ were higher than for 3D6 $(65.5 \pm 17.3 \mu \mathrm{g} / \mathrm{ml})$, indicating that the lack of impact on plasma $A \beta 40$ was not due to lower plasma levels of SAR255952. Such findings are consistent with the specificity of SAR255952 for protofibrillar and fibrillar $\mathrm{A} \beta$ forms versus LMW and monomeric conformations present in the circulation.

\section{Prevention of synaptic activity deficits by SAR255952 treatment}

The functional impact of the prevention of amyloid pathology by SAR255952 was next assessed. Due to the hyperreactivity of the APPSL mouse line and the repeated animal manipulations for treatment (even in the case of weekly administrations), cognitive testing in Object Recognition assay could not be interpreted. Hippocampal synaptic function was evaluated by electrophysiology in brain slices. Treatments with SAR255952 (initiated at 2 months of age) were extended in a subgroup of animals to the age of 9-10 months when strong deficits in synaptic function have developed. In ex-vivo hippocampal brain slices prepared from Ctl-IgG1-treated APPSL transgenic mice, a marked deficit was observed in the glutamatergic synaptic transmission at the level of the CA3-CA1 synapse, the main excitatory pathway in hippocampus. Treatment with SAR255952 prevented the functional alteration to a partial, but significant extent. The protective effect of SAR255952 was visible at all suprathreshold stimulation intensities that elicited measurable field potentials on the stimulation/response curve (Fig. 4a). Measurement of the size of the EPSPs at the intermediate stimulation intensity of $250 \mu \mathrm{A}$ indicated that APPSL mice chronically treated with Ctl-IgG1 displayed a $-62 \%$ reduction with respect to wild-type controls $(1.6 \pm 0.26 \mathrm{mV}$ versus $0.61 \pm 0.11 \mathrm{mV}$, respectively, mean \pm SEM, $p<0.05$, Fig. $3 b)$. Treatment with $3 \mathrm{mg} / \mathrm{kg}$ and $10 \mathrm{mg} / \mathrm{kg}$ SAR255952 provided a dose-dependent protection against the loss of synaptic function. At the highest tested dose, EPSP sizes reached $0.96 \pm 0.17 \mathrm{mV}$, a significant $+35 \%$ recovery with respect to Ctl-IgG1-treated animals $(p<0.05)$. In animals treated with the same dose of 3D6 $(10 \mathrm{mg} / \mathrm{kg})$, the size of the EPSPs reached $0.78 \pm 0.09 \mathrm{mV}, \mathrm{a}+17 \%$ trend for improvement with respect to Ctl-IgG1 controls which did not reach significance ( $p>0.17$, Fig. $4 \mathrm{~b})$. 
A
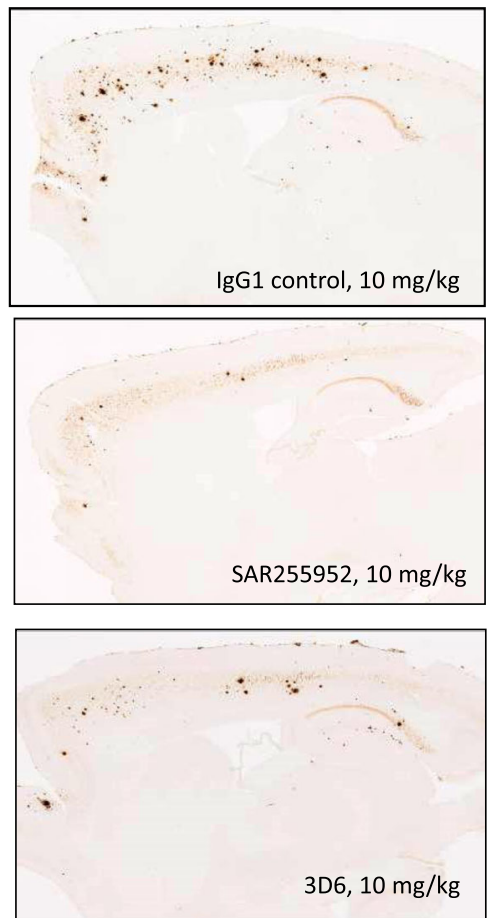

B

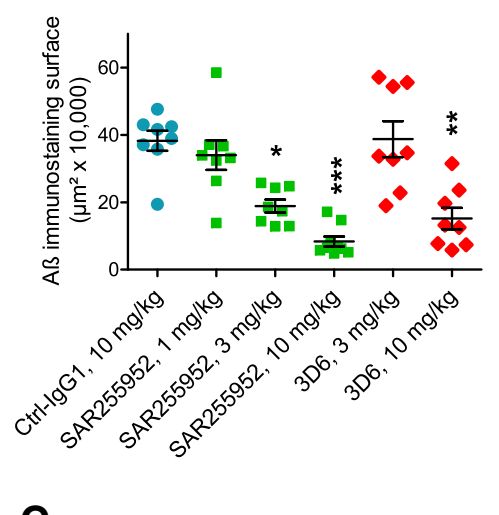

C

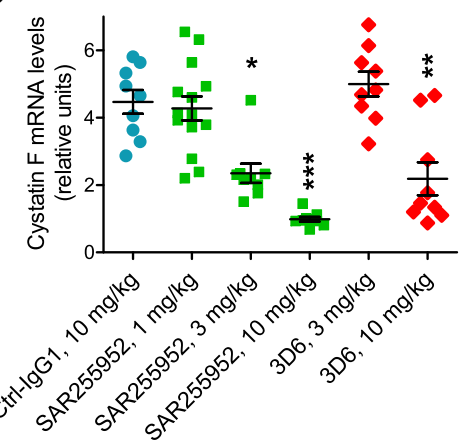

Fig. 3 Chronic treatment with SAR255952 prevents amyloid $\beta$ (A $\beta$ ) peptide plaque deposition and brain microglial activation in APPSL transgenic Alzheimer's mice. Animals were treated for 20 weeks once weekly by the intraperitoneal route with the indicated doses of antibodies starting from the age of 2 months. a Whole scanned $A \beta$-immunostained sagittal brain tissue section illustrating the decrease in the extracellular $A \beta$ peptide deposition process in both cortical and hippocampal brain areas of representative mice chronically treated either with SAR255952 or 3D6, with respect to Ctrl-IgG1-treated mice. $\mathbf{b}$ Mean values of the total surface occupied by A immunostaining measured over the whole cortical area from eight sections per animal. $\mathbf{c}$ Real-time PCR amplification of the brain inflammation marker cystatin F expression in the hippocampus. Statistical analysis of both histological and biochemical measurements denotes the significant effect of SAR255952 at 3 and 10 mg/ $\mathrm{kg}$ injected doses in the cortex. The 3D6 effect is significant at $10 \mathrm{mg} / \mathrm{kg} .{ }^{*} p<0.05,{ }^{* *} p<0.01,{ }^{* * *} p<0.001$, versus Ctrl-lgG1-treated controls. Horizontal black lines and error bars denote mean \pm SEM data

In-vivo penetration of SAR255952 in brain parenchyma of APPSL mice

Using in-vivo two-photon microscopy, the pharmacokinetics of fluorescently labeled SAR255952 was evaluated in three distinct compartments of one female APPSL mouse: 1) brain parenchyma; 2) perivascular deposits; and 3) parenchymal plaques. We found that $30 \mathrm{~min}$ after the i.v. injection the labeled antibody was readily detectable in cortical vessels (Fig. 5a). During a follow-up imaging session (24 h after dosing), we observed accumulation of labeled antibody in the brain parenchyma and at the perivascular amyloid deposits. Two additional imaging sessions, performed at 72 $\mathrm{h}$ and $144 \mathrm{~h}$ after dosing, revealed that the antibody accumulated on parenchymal plaques, while the level of parenchymal fluorescence declined from its peak level observed at $24 \mathrm{~h}$ (Fig. 5a, c). Thus, the parenchymal antibody fluorescence was significantly lower than the plaque-associated antibody fluorescence at $72 \mathrm{~h}$ and $144 \mathrm{~h}(p<0.01)$. This finding is consistent with gradual removal of unbound antibody from the parenchyma and/or redistribution of antibody from the parenchymal compartment onto plaques. Similar in-vivo labeling of amyloid plaques with peripherally administered antibody was also recently demonstrated with another anti-protofibrillar antibody (aducanumab) with no plaque binding with a control IgG [42]. Interestingly, labeled SAR255952 predominantly accumulated on the peripheral parts of parenchymal $A \beta$ plaques (Fig. $5 \mathrm{~b}$ ) and remained there for at least $144 \mathrm{~h}$ (7 days), suggesting that chronic weekly treatments might lead to progressive drug accumulation.

Indeed, on brain sections from a 4-month chronic in-vivo study with SAR255952, immunohistochemistry labeling with anti-IgG1 and Congo red histology revealed that most remaining congophilic plaques were decorated with IgG1 labeling (Fig. 6). In contrast, absolutely no IgG1 immunoreactivity was detectable over 


\section{Synaptic function in hippocampus}
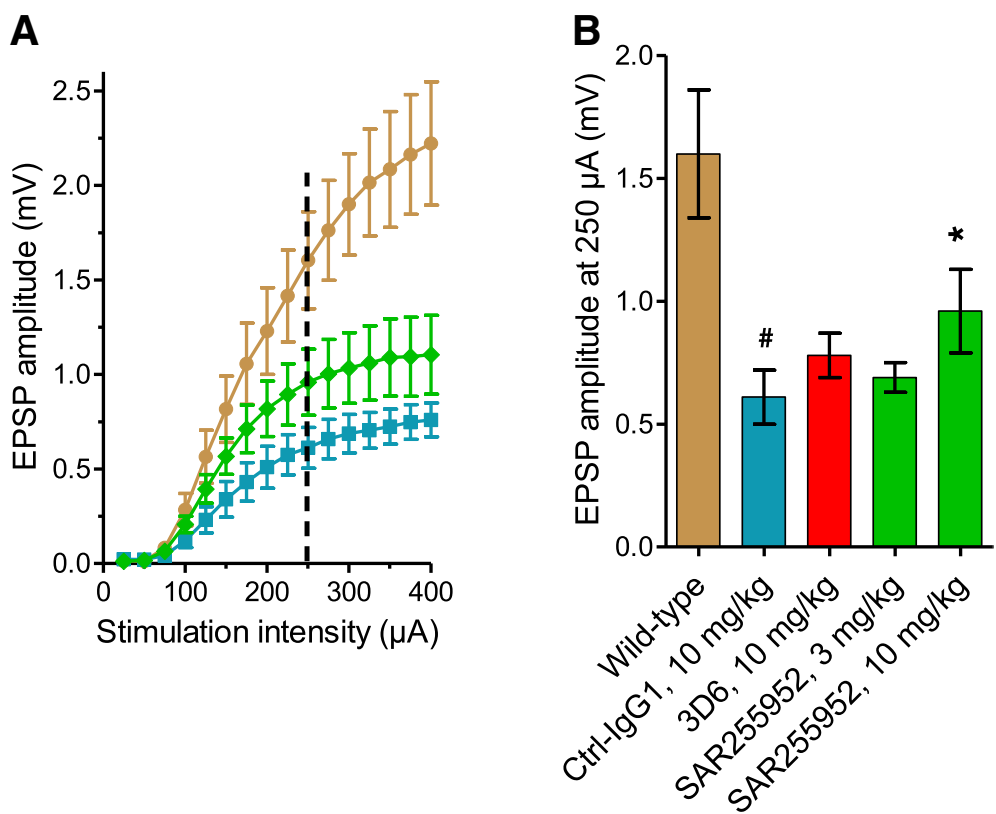

Fig. 4 Chronic treatment with SAR255952 prevents synaptic activity deficits in APPSL mice. A subgroup of the transgenic animals was maintained under treatment up to the age of 9-10 months for ex-vivo hippocampal brain slice electrophysiology. a Mean ( \pm SEM) size of the extracellular field excitatory postsynaptic potentials (EPSP) recorded in the CA1 stratum radiatum in response to electrical stimuli of the indicated intensity applied to the Schaeffer collaterals of wild-type controls (brown circles), Ctrl-lgG1-treated controls (blue squares), or animals treated with 10 mg/ kg i.p. SAR255992 (green diamonds). b Mean ( \pm SEM) amplitude of the EPSP at the intermediate stimulation intensity of $250 \mu A$ (dotted line on a). ${ }^{\#} p<0.05$, versus wild-type controls; ${ }^{*} p<0.05$, versus Ctrl-lgG1-treated controls

Congo red stained parenchymal deposits in Ctlr-IgG1treated animals, as illustrated in Fig. 6e.

Altogether, these data support the concept that systemically administered SAR255952 can cross the blood-brain barrier, diffuse in the parenchyma, and reach amyloid plaques in native tissues, which leads to a progressive accumulation of antibodies on the target.

\section{Prevention of amyloid plaque development in vivo by humanized SAR228810}

Since significant biological differences might exist in the low level of effector functions between a murine aglycosylated IgG1 and a human hIgG4 with an engineered Fc domain, it was important to demonstrate activity of the humanized SAR228810 in vivo and to compare it with the murine version. As adapted from previous reports [39], immunotolerization of APPSL transgenic mice with anti-CD4 transient immunodepletion enabled a 4-month weekly treatment with SAR228810 without immune reaction against the test article; at end of treatment, 1 day following the last administration, plasma levels of humanized SAR228810 $(414 \mu \mathrm{g} / \mathrm{ml})$ were similar to levels of murine SAR255952 $(504 \mu \mathrm{g} / \mathrm{ml})$ while, in non- tolerized mice, SAR228810 plasma levels were minimal after 4-weekly administrations.

Quantification of brain $A \beta$ peptide deposition by immunohistochemistry confirmed that immunotolerization by itself had not affected $A \beta$ peptide deposition in APPSL transgenic mice. When compared with Ctl-IgG1, treatments with SAR228810 and SAR255952 markedly reduced extracellular $\mathrm{A} \beta$ peptide deposition in the cortex $(-63 \%, p=0.0009$, and $-65 \%, p=0.0015$, respectively, Table 4), in the hippocampus $(-67 \%, p=0.0016$, and $-73 \%, p=0.0005$, respectively, Fig. 7), and in the thalamus $(-83 \%, p=0.0004$, and $-71 \%, p=0.0074$, respectively) (data not shown).

In the hippocampus, immunotolerization did not affect cystatin $\mathrm{F}$ mRNA levels and, compared with control IgG, treatment by SAR255952 or SAR228810 reduced cystatin $\mathrm{F}$ mRNA levels by $-66 \%$ and $-70 \%(p<$ 0.0001 ), respectively (Fig. 7c, Table 4), confirming the decrease in plaque-associated inflammation.

The humanized IgG4 antibody SAR228810 therefore had a similar activity at preventing amyloid plaque deposition than the mouse aglycosylated SAR255952, strongly suggesting that low to very low effector functions were sufficient to maintain in-vivo efficacy. 


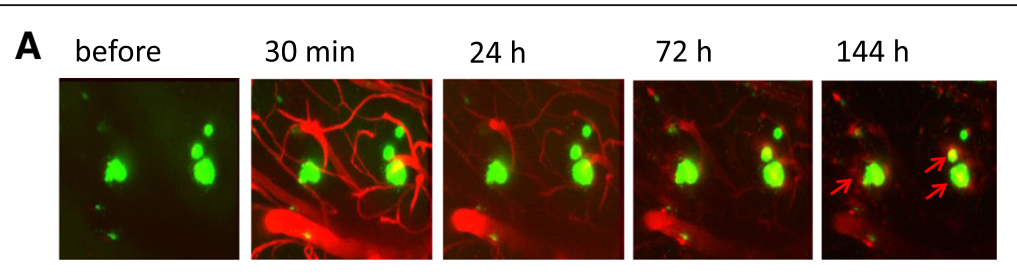

Green: amyloid plaques labelled with Methoxy-X04 Red: 13 C3 antibody labelled with DyeLight-649
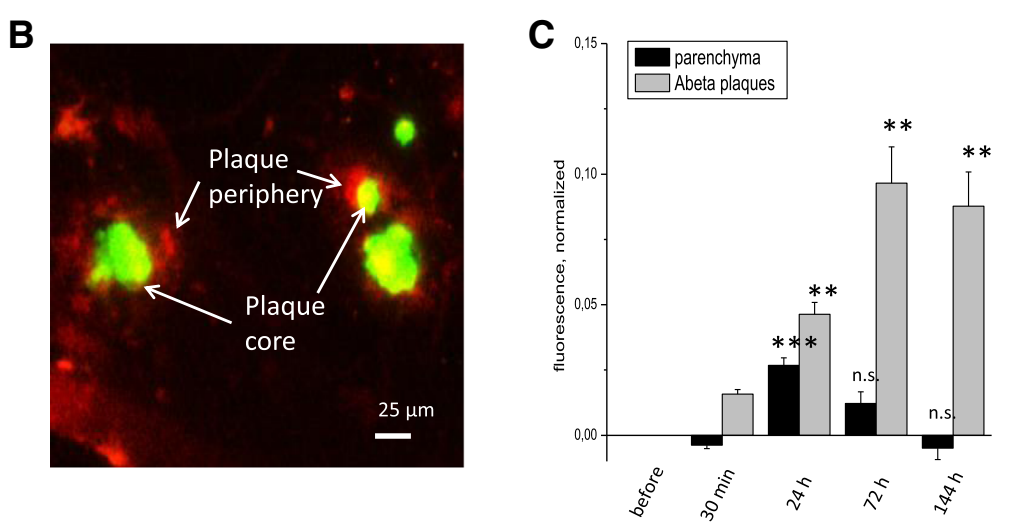

Fig. 5 In-vivo penetration of SAR255952 in brain parenchyma and long-lasting binding to amyloid plaques in the cortex of APPSL mice. a Successive imaging sessions performed prior to and following the i.v. administration of SAR255952 labeled with Dyelight-649 (red); amyloid plaques labeled by Methoxy-XO4 (green). b Higher magnification image showing that SAR255952 (red) decorates Aß plaques (green) $144 \mathrm{~h}$ after i.v. administration. c Quantification of temporal changes in the antibody-DyeLight-649 fluorescence showing that SAR255952 accumulates on amyloid plaques while being cleared from the parenchyma. ${ }^{* *} p<0.01,{ }^{* * *} p<0.005$, versus . n.s. not significant

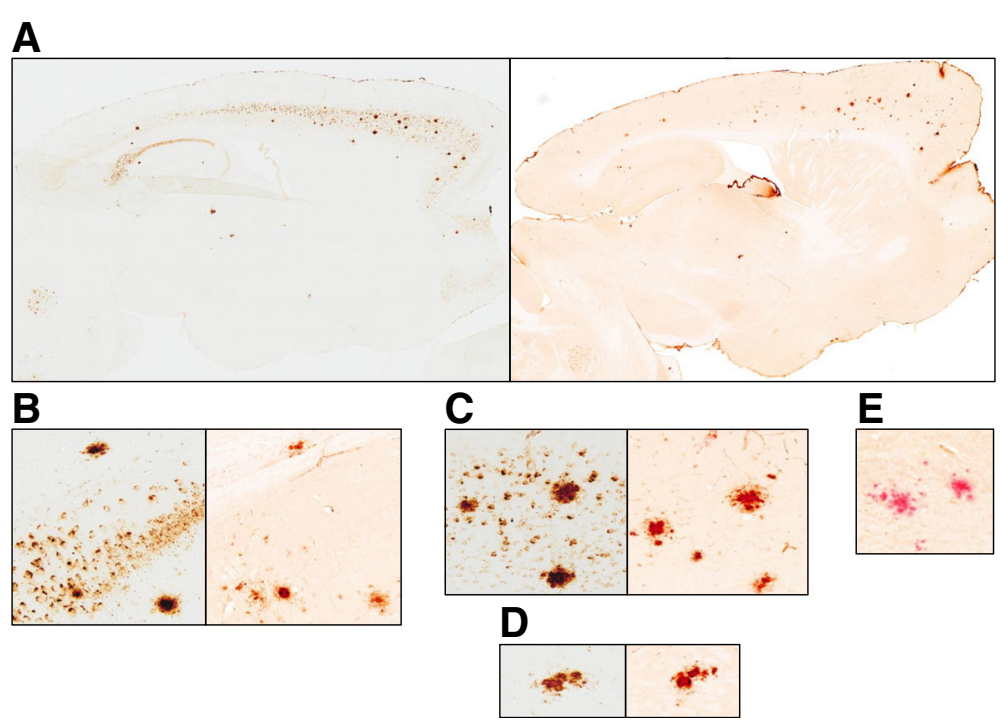

Fig. 6 Histological demonstration of SAR255952 brain penetration after chronic peripheral administrations (4-month weekly i.p., $10 \mathrm{mg} / \mathrm{kg}$ ) in young male APPSL mice. a Serial wholly-scanned sagital brain tissue sections with either A 3 (left panel) or lgG1 and Congo red (right panel) immunostaining of one representative animal of the SAR255952-treated group. b-d Higher magnification views of individual hippocampal, cortical, and occasional thalamic plaques, respectively showing all remaining plaques with Congo red-positive central core decorated with IgG1 immunostaining. e High magnification view of individual plaques in one representative animal chronically treated with Ctrl-lgG1 antibody. Only Congo red- positive central cores of amyloid deposits were detected 
Table 4 Prevention of amyloid accumulation and microglial activation by SAR255952 and its human homolog SAR228810 in immunotolerized and non-immunotolerized APPSL transgenic mice

\begin{tabular}{|c|c|c|c|c|c|c|}
\hline & Treatment groups & No. of animals & Mean value & \pm SEM & Effect size & $p$ value \\
\hline \multicolumn{7}{|c|}{ Amyloid $\beta$ immunohistochemistry total area cortex $\left(\mu m^{2}\right)$} \\
\hline Non-immunotolerized & Ctrl-lgG1 & 8 & 696,471 & 81,813 & & \\
\hline Immunotolerized & Ctrl-lgG1 & 9 & 569,092 & 63,738 & $-18 \%$ vs non-immunotolerized & NS \\
\hline Immunotolerized & SAR228810 & 8 & 207,996 & 27,252 & $-63 \%$ vs immunotolerized DM4 & $<0.001$ \\
\hline Immunotolerized & SAR255952 & 8 & 197,600 & 17,064 & $-65 \%$ vs immunotolerized DM4 & $<0.001$ \\
\hline \multicolumn{7}{|c|}{ Cystatin F mRNA hippocampus (related units) } \\
\hline Non-immunotolerized & Ctrl-lgG1 & 12 & 78 & 7.5 & & \\
\hline Immunotolerized & Ctrl-lgG1 & 12 & 80 & 8.9 & $+3 \%$ vs non-immunotolerized & NS \\
\hline Immunotolerized & SAR228810 & 12 & 24 & 3.2 & $-70 \%$ vs immunotolerized DM4 & $<0.001$ \\
\hline Immunotolerized & SAR255952 & 9 & 28 & 2.8 & $-66 \%$ vs immunotolerized DM4 & $<0.001$ \\
\hline
\end{tabular}

All animals were treated with the same dose $(10 \mathrm{mg} / \mathrm{kg})$ of the indicated antibodies NS not significant, SEM standard error of the mean

\section{In-vivo safety study with SAR255952 including brain microvessel liability}

The main safety concerns with several anti-A $\beta$ mAbs, such as bapineuzumab, gantenerumab, or aducanumab, have been brain vasogenic edema and microhemorrhages (ARIA). It has been suggested that antibody/ Fc-receptor binding to microglia and subsequent immune activation at perivascular amyloid deposits are key events in $A \beta$ antibody-mediated microhemorrhages. In the present study, i.v. (bolus) administration of SAR255952 (at doses of 10,20 , or $50 \mathrm{mg} / \mathrm{kg}$ ) or 3D6 (40 $\mathrm{mg} / \mathrm{kg}$ ) in aged (12-13 months old at initiation of dosing) APPSL transgenic mice once a week for 9 consecutive weeks did not result in any compound-related in-life changes (i.e., mortality, clinical signs, body weight, and food consumption), or any hematology, clinical chemistry, or anatomic pathology findings (i.e., organ weight changes, or macroscopic and microscopic findings). As expected for transgenic APPSL mice of this age, amyloid plaques were noted in all treated animals as rounded, pale eosinophilic, acellular, variably sized areas in the cerebral cortex, hippocampus, and thalamus. Thalamic amyloid plaques were occasionally centered on basophilic material. Minimal brain parenchymal
A
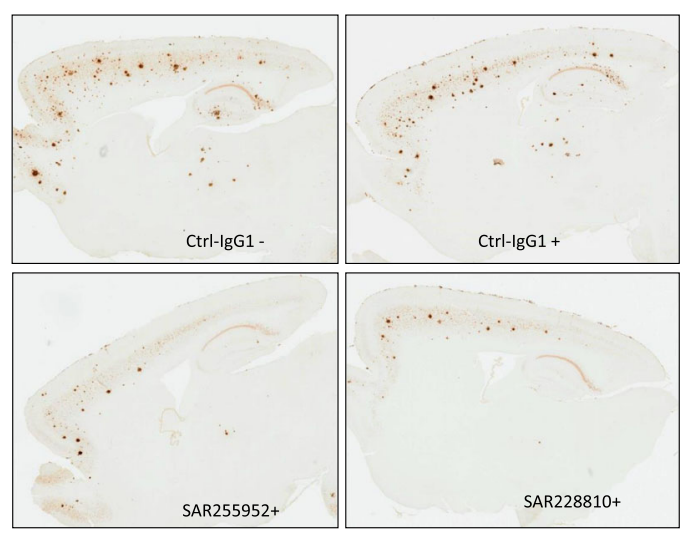

B

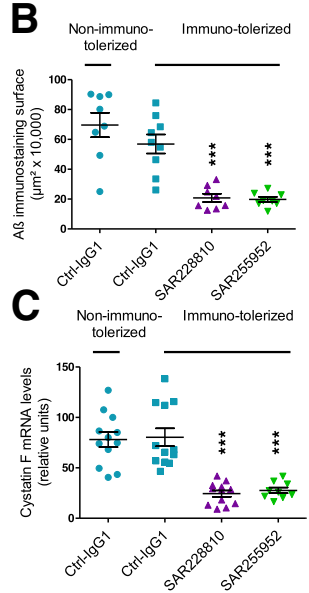

Fig. 7 SAR228810, the humanized version of SAR255952, has consistent activity in immunotolerized APPSL mice. Animals were depleted in immunocompetent cells by treatment with a monoclonal anti-CD4+ antibody before undergoing a weekly treatment with $10 \mathrm{mg} / \mathrm{kg}$ i.p. of the indicated amyloid $\beta(A \beta)$ antibodies (labeled + in the micrographs). a Representative whole-scanned AB-immunostained sagittal brain tissue section illustrating the decrease in the extracellular $A \beta$ peptide deposition process in cortical, hippocampal, and thalamic brain areas in representative immunotolerized mice chronically treated either with SAR255952 or SAR228810, in respect to immunotolerized or not Ctrl-igG1treated mice. $\mathbf{b}$ Mean values of the total surface occupied by $A \beta$ immunostaining measured in the cortex over eight sections per animal. The immunodepletion has no significant effect on the cortical A $\beta$ peptide deposition process in Ctrl-lgG1-treated mice. c Mean \pm SEM real-time PCR amplification readings for the brain inflammation marker cystatin $\mathrm{F}$ expression in the hippocampus. Statistical analysis denotes similar significant effects of both SAR228810 and SAR255952. Of note, there was no major effect of the immunotolerization on A peptide deposition in the brain of APPSL mice. ${ }^{* *} p<0.01,{ }^{* * *} p<0.001$, versus Ctrl-lgG1-treated controls. Horizontal black lines and error bars denote mean \pm SEM data 
hemorrhagic (Perl's positive) foci were noted in the brain of mice in the PBS control-and SAR255952-treated groups (with the same incidence and severity). In contrast, in 3D6-treated mice, microscopic vascular changes were detected and consisted of hyalinization of the media in meningeal and/or cerebral arteries associated with degeneration/necrosis of vessel walls in 4 out of 13 mice (Fig. 8a), mild meningeal hemorrhage was observed in the olfactory bulb from the most severely affected animal (data not shown), and an increased incidence of Perl's-positive staining around vascular structures in association with perivascular inflammation was seen (Fig. 8b, c). Thickening of vessel walls and vasculitis in the vicinity of cerebral amyloid angiopathy-affected blood vessels have also been previously reported [43].

\section{Discussion}

Anti-A $\beta$ immunotherapy represents a major approach in current AD drug development but has had only mitigated clinical success so far. We present here the biochemical and pharmacological properties of a novel antibody, SAR228810, and its murine precursor, SAR255952. They have been selected and engineered to address some of the proposed limitations of current clinical mAbs: 1) specificity for soluble protofibrillar and fibrillar $\mathrm{A} \beta$ assemblies/conformations associated with $\mathrm{AD}$ pathology to increase efficacy and brain bioavailability; and 2) drastically reduced effector functions to further limit ARIA risks, thereby enabling higher tolerated doses.

Due to its biophysical properties, $A \beta$ peptide (the $A \beta 40$ or $A \beta 42$ isoforms) can form a very broad spectrum of assemblies ranging from monomeric to low and high-n oligomers, soluble protofibrils, and insoluble diffuse deposits to aggregated plaques [11]. However, these different conformations lack a robust biophysical characterization, are highly dependent on experimental conditions, and the presence of some of them in pathological tissues has not been demonstrated [11]. It remains highly debated which $A \beta$ conformation(s) should be neutralized/cleared for therapeutic benefit. Starting with brain pathology studies, soluble oligomeric forms of $A \beta$ have attracted renewed attention. Initially, in case-control studies, brain soluble $A \beta$ levels were correlated with $\mathrm{AD}$ dementia [12, 13]. More recently in a series of autopsy cases selected with a similar brain amyloid load, high brain soluble oligomeric $A \beta$ was shown to differentiate demented $(C D R>1)$ versus non-demented $(\mathrm{CDR}=0)$ cases [14]. Brain soluble oligomeric $A \beta$ was shown to have a strong functional impact, inhibiting acute development of long-term potentiation in vitro and in vivo and leading to neuronal neurite disruption [15-18]. These A $\beta$ high molecular weight soluble species are still under characterization $[19,20]$ but

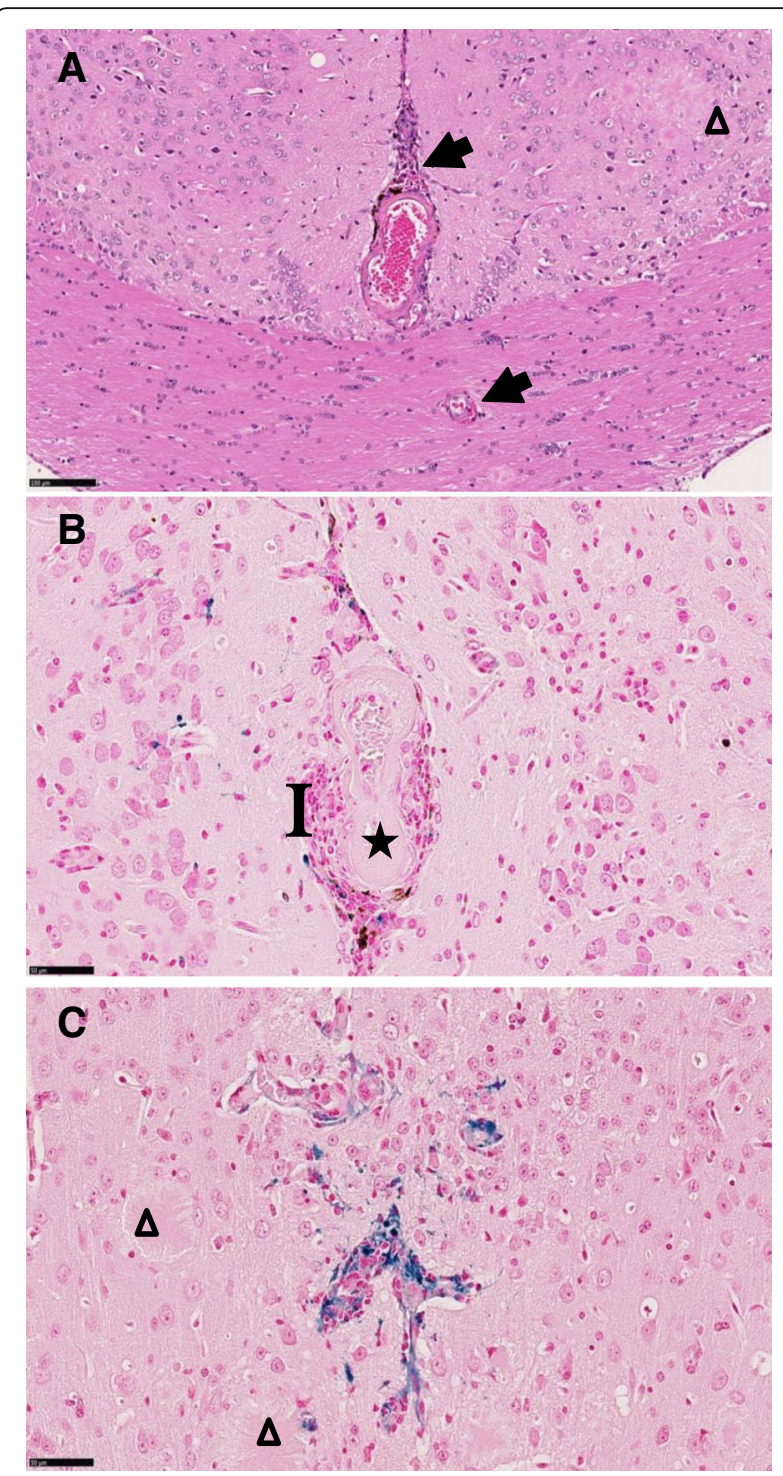

Fig. 8 Unlike 3D6, SAR255952 does not cause brain microvessel alterations. Representative histopathological events induced by 3D6 antibody after chronic treatment of 12-month-old female APPSL mice. a Perivascular microhemorrhages (arrows) with inflammatory infiltrates and arterial vessel wall degeneration, meningeal and cerebral arteries. Triangles represent amyloid plaques (hemalum, eosin and saffron). $\mathbf{b}, \mathbf{c}$ Periarteriolar iron remnants of hemorrhage in blue. Note arteriolar media hyalinization (*) and perivascular inflammatory cell infiltrates (I) (Perl's stain for iron with fast red nuclear counterstaining). Scale bars represent $100 \mu \mathrm{m}$ in panel A and $50 \mu \mathrm{m}$ in panels $\mathbf{b}$ and $\mathbf{c}$

would represent key candidates to be neutralized for therapeutic benefit.

The binding profile of anti- $\mathrm{A} \beta \mathrm{mAbs}$ to the different A $\beta$ conformations has been recently reviewed [4] and summarized herein in the Background section. In comparison, SAR228810 binds specifically to soluble high molecular weight protofibrils and fibrillar $A \beta$ versus 
monomeric $A \beta$ and does not recognize diffuse deposits in human brains.

SAR228810 shows a high selectivity versus monomeric $A \beta$ with no detectable binding to monomeric $A \beta$ by surface plasma resonance and with approximately 100-fold selectivity in ELISA assays, a likely underestimation since monomeric $A \beta$ preparation is subject to early aggregation on adhering to plastic wells in the ELISA format. In comparison, gantenerumab and BAN2401 retain some limited affinity for monomeric $A \beta$. SAR228810 selectivity versus monomeric $A \beta$ is further confirmed in vivo where it does not increase plasma $A \beta$ levels unlike monomeric $\mathrm{A} \beta$-binding $\mathrm{mAs}$ such as bapineuzumab (used here as a positive control), solanezumab, or crenezumab [4] that bind to plasma $A \beta$ and prevents its degradation/clearance in liver [41]. In immunohistology, SAR228810 (up to $5 \mu \mathrm{g} /$ $\mathrm{ml}, 35 \mathrm{nM}$ ) did not display binding to diffuse $A \beta$ deposits common in elderly cases and which are not related to $\mathrm{AD}$ pathology, further documenting that SAR228810 does not bind to $A \beta$ assemblies devoid of $\beta$-sheet conformation. In comparison, gantenerumab, in line with its low affinity for monomeric $A \beta$, has been reported to bind to both diffuse $\mathrm{A} \beta$ deposits and compact plaques at $1 \mu \mathrm{g} / \mathrm{ml}(7 \mathrm{nM})[8]$, in addition to cross-reactivity on neurons [44], documenting significant differences in binding profile with SAR228810.

Of interest, SAR228810 neutralizes the neurotoxicity of synthetic oA $\beta 42$ in cultures and prevents development of synaptic dysfunction in vivo in amyloid transgenic mice. While the three protofibrillar $A \beta$ mAbs neutralized oA $\beta 42$ neurite toxicity, only SAR228810 prevented neuronal apoptosis, further suggesting differences in the binding profiles of the three mAbs across the wide spectrum of $A \beta$ oligomer/protofibril conformers. However, it will be important in the future to compare the binding profiles of those mAbs, including aducanumab, with the different multimeric $A \beta$ assemblies and in particular their capacity to neutralize $\mathrm{AD}$ brain-derived synaptotoxic oA $\beta$.

\section{Brain bioavailability}

As previously reported for IgG [45], the murine version of SAR228810 had detectable but low brain penetration, representing approximately $0.03-0.1 \%$ of plasma levels. In transgenic mice, 7 days following dosing at $10 \mathrm{mg} / \mathrm{kg}$, SAR255952 concentrations in CSF were in the range of $150-300 \mathrm{ng} / \mathrm{ml}$. In live imaging in mice bearing amyloid plaques, we could document a slow accumulation over days of labeled SAR255952 to the periphery of cerebral amyloid plaques while parenchymal levels decreased and antibody was cleared from plasma. Finally, after chronic treatment in transgenic mice, a strong amyloid plaque-associated IgG1 immunoreactivity could be detected, indicating SAR255952 localization to cerebral plaques.
Due to the measurable but low brain penetration, the antibody selectivity among the different $A \beta$ pools/conformations (which have extremely different ranges of concentrations in the brain as mentioned in the Background section) has a direct impact on its bioavailability in vivo to neutralize/clear each of the cerebral $A \beta$ pathological assembly types. For instance, at the clinical dose of $2 \mathrm{mg} / \mathrm{kg}$, CSF bapineuzumab concentration was 45 $\mathrm{ng} / \mathrm{ml}(0.25 \mathrm{nM})$ [46], well below the concentration of monomeric $A \beta$ in human CSF (approximately $10 \mathrm{ng} / \mathrm{ml}$, $2.5 \mathrm{nM}$ ), and, therefore, most bapineuzumab molecules would be $A \beta$-bound when reaching the brain parenchyma with limited brain bioavailability to neutralize soluble oligomeric and protofibrillar forms. We would like to emphasize the issue of low therapeutic IgG bioavailability for central nervous system (CNS) indications. It is useful to recall that, for the rare disease amyloid IgG light chain (LC) amyloidosis affecting peripheral organs, the aggregated LC antibody NEOD0001 has recently shown some early signs of efficacy at a monthly dose of $24 \mathrm{mg} / \mathrm{kg}$ [47], while IgG penetration in target organs (the kidney and heart) is known to be in the order of 0.1 to 0.5 compared with plasma levels, at least ten-fold higher than for the brain [45]. The recent positive clinical results for aducanumab decreasing brain amyloid in patients were dose-dependent and strongly significant at the highest doses of 6 and $10 \mathrm{mg} / \mathrm{kg}$ [7], and similarly for BAN2401 active only at the highest dose $(10 \mathrm{mg} / \mathrm{kg})$ tested ([10]), although both had ARIA occurrence. Indeed, the $A \beta$ immunotherapy field is now recognizing this major limitation with a recent trend to largely increase doses when tolerated [48].

The issue of therapeutic antibody bioavailability is further exacerbated by dose limitations due to ARIA adverse effects observed in clinical studies for antibodies binding to vascular amyloid and with effector functions (bapineuzumab from the dose of $2 \mathrm{mg} / \mathrm{kg}$, gantenerumab and aducanumab in clinical studies $[26,49])$. To limit the risk of ARIA, SAR228810 was engineered with a double mutant human IgG4 Fc domain to endow drastically reduced effector functions which did not compromise its activity at preventing amyloid plaque development in vivo. Using murine versions, SAR255952 (aglycosylated mIgG1 with very low effector functions) was even moderately more potent than a 3D6 mIgG2a control (murine bapineuzu$\mathrm{mab}$ ) and only minimally less potent than the complete mIgG1 version of SAR255952 (data not shown), the latter two possessing significant high effector functions. Along with amyloid plaque lowering, microglial and astrocyte inflammation were decreased as well as plaque-associated dystrophic neurites, leading to improved synaptic function in the hippocampus. In the animal model used, the impact on cognitive deficit could not be assessed, however. Of note, the human antibody SAR228810 was also shown in 
vivo to have similar activity as murine SAR255952 using immunotolerized mice. As expected, even at high doses, SAR255952 did not induce brain microhemorrhages and vasculitis while murine bapineuzumab did, similar to its humanized form inducing ARIA in patients.

Unlike in previously reported in-vitro phagocytosis studies, multiple lines of evidence support that effector functions of anti- $\mathrm{A} \beta \mathrm{mAb}$ are not necessary for activity on amyloid plaques in vivo (discussed in [28]). Using in-vivo multiphoton microscopy, Bacskai and colleagues [50] have demonstrated that 3D6 F(ab') $)_{2}$ fragments (that lack the Fc region of the antibody and therefore effector functions) led to clearance of nearly half of amyloid deposits in APP mice within 3 days, similar to the results obtained with full-length 3D6. These data could be extended to the chronic setting where intraperitoneal chronic treatment with the $F\left(a b^{\prime}\right) 2$ fragment of an $A \beta$ mAb significantly reduced cerebral amyloid plaques, similar to full IgG mAb [51]. Similarly, brain expression of anti-A $\beta$ single chain antibody variable domain (lacking a Fc domain) was also efficacious in amyloid transgenic models [52]. These findings are also consistent with early active immunization data where $A \beta$ immunization was as effective at reducing amyloid deposition in APP mice with FcR- $\gamma$ chain knockout $\left(\mathrm{FcR}-\gamma^{-} /^{-}\right)$as in Fc $\gamma \mathrm{R}$-sufficient APP mice [53]. Additionally, the deglycosylated anti- $\mathrm{A} \beta 2 \mathrm{H} 6$ (therefore with low effector functions) had an activity comparable to fully glycosylated $2 \mathrm{H} 6$ with regard to clearance of brain amyloid plaque and reversing behavioral deficits in the transgenic model [54]. The deglycosylated IgG, however, had the clear advantage of not inducing brain microhemorrhages, similar to that demonstrated in the present report with SAR228810/SAR255952. A similar strategy was adopted for crenezumab which was engineered with a human IgG4 isotype while retaining efficacy in animal studies [55]. A low effector function variant of bapineuzumab (AAB003) developed ARIA-E at higher doses than its parent antibody, confirming that reduced effector function would lower ARIA risk but was discontinued for a lack of effect on biomarkers, suggesting that both epitope and level of effector function could be important [56].

Conceptually, if the therapeutic intent is to neutralize the brain soluble form of synaptotoxic $A \beta$, there would be a limited requirement for IgG effector function that could even be detrimental in the $\mathrm{AD}$ brain which presents a significant inflammatory-primed cerebral environment. Indeed, in aging and in chronic neurodegenerative diseases, modest challenges can lead to more profound CNS inflammation and cognitive deficits than in healthy young individuals, a phenomenon named microglia priming [57]. In acute studies, a full IgG anti-A $\beta$ mAb induced a significant increase in brain immune cells while the corresponding $\mathrm{F}(\mathrm{ab}$ ')2 fragment did not, while maintaining efficacy on amyloid plaques [51]. Similarly for tau mAbs, it was demonstrated that effector-less IgG maintained efficacy without leading to the neurotoxic activation of microglia triggered by effector-competent IgG [58]. Overall, these results suggest that targeting amyloid in vivo might not require Fc-dependent effector functions.

Regarding the mechanism of action of SAR228810, its binding to soluble protofibrillar $A \beta$ assemblies could prevent further aggregation and synaptotoxicity. In addition, by binding/coating existing plaques, SAR228810 would have the potential to block/prevent secondary $\mathrm{A} \beta$ nucleation generated at the plaque surface [59] that could be related to the periplaque protofibrillar A $\beta 42$ "hot spots" associated with axonal dystrophies [60]. It could also prevent leakage from plaques of the $\mathrm{o} A \beta$ assemblies associated with dementia that have recently been identified in the human AD brain [14]. In this regard, blocking $A \beta$ monomer production, such as with a BACE inhibitor, might be ineffective at preventing the release of toxic species from plaques.

Translating to human AD clinical studies where patients have a high cerebral amyloid deposition many years prior to the onset of symptoms, we are aware that the efficacy of SAR228810 was demonstrated only as a prevention of plaque accumulation and synaptic dysfunction but not for reduction of preexisting amyloid plaque load in the very aggressive APP transgenic line used. There are actually very limited data in the literature demonstrating that in amyloid transgenic mice peripheral administration of an anti- $\mathrm{A} \beta \mathrm{mAb}$ can decrease preexisting amyloid burden. Even for aducanumab, that has demonstrated a clear doseand time-dependent decrease of amyloid positron emission tomography (PET) burden in patients, its murine chimeric version could not decrease preestablished amyloid plaque load after systemic administration [42], while being able to prevent plaque accumulation when administered preventatively [7]. The transgenic strains have been designed with very high $\mathrm{A} \beta$ production to develop plaques in a few months versus many decades in humans, and only in conditions where $A \beta$ production was stopped or blocked concomitantly could immunotherapy decrease brain amyloid [61, 62]. Of interest in the therapeutic conditions mentioned above, aducanumab improved neuronal calcium levels [42] that could be linked to the cognitive effect in patients, possibly separate from amyloid clearance itself. In the future, it will be important to compare the different high molecular weight $A \beta$ assembly preferring antibodies in more detail and in particular for neutralizing the soluble AD brain synaptotoxic species.

\section{Conclusions}

SAR228810 is a novel antibody with high selectivity for soluble protofibrillar and fibrillar $A \beta$ conformations that has been engineered with drastically reduced effector functions. The expected lack of ARIA in patients could allow us to safely increase antibody doses and, together 
with the binding selectivity, should lead to a more potent neutralization of brain $A \beta$ species than the antibodies currently in clinical development. SAR228810 and its murine version can neutralize synthetic oA $\beta$ neurotoxicity and in animal models prevent amyloid plaque accumulation, related inflammation, and synaptic dysfunction. The potential to block the release/neutralize synaptotoxic $A \beta$ species from amyloid plaques provide rationale for benefit in patients with existing brain amyloid in comparison with small-molecule inhibitors of $A \beta$ production. For clinical studies, SAR228810 target engagement markers such as the capture of high molecular weight soluble $A \beta$ or markers of brain synaptic activity might be more appropriate than amyloid PET. Based on this attractive profile, a first-in-man clinical study has been initiated in AD patients (NCT01485302).

\section{Additional file}

Additional file 1: Table S1. Affinity of SAR228810 and SAR255952 for the respective FcyRs. Table S2. SAR255952 prevents accumulation of the three $A \beta$ subspecies ( $A \beta 38, A \beta 40$, and $A \beta 42$ ) in soluble and insoluble brain fractions in APPSL transgenic mice. (DOCX $42 \mathrm{~kb}$ )

Additional file 2: Figure S1. Unlike murine bapineuzumab, SAR255952 does not increase peripheral circulating amyloid levels in APPSL transgenic mice. Blood was drawn from animals treated for 4 months once weekly by an intraperitoneal route with the indicated doses of antibodies starting from the age of 2 months. Horizontal black lines and error bars denote mean \pm SEM of data. (PPTX $58 \mathrm{~kb}$ )

\section{Abbreviations}

ACSF: Artificial cerebrospinal fluid; AD: Alzheimer's disease; ARIA: Amyloidrelated imaging abnormalities; $A B$ : Amyloid $\beta ; B S A$ : Bovine serum albumin; CSF: Cerebrospinal fluid; DAB: Diaminobenzimide; DMEM: Dulbecco's modified Eagle's medium; DMSO: Dimethylsulfoxide; ELISA: Enzyme-linked immunosorbent assay; EPSP: Excitatory postsynaptic potentials; FDA: Food and Drug Administration; FFPE: Formalin-fixed and paraffin-embedded; FITC: Fluorescein isothiocyanate; GH: Guanidine hydrochloride; HMW: High molecular weight; HRP: Horseradish peroxidase; i.p.: Intraperitoneal; i.v.: Intravenous; IAPP: Islet amyloid polypeptide; IgG: Immunoglobulin G; IHC: Immunohistochemistry; mAb: Monoclonal antibody; MAP2: Microtubule associated protein 2; OAB: Oligomeric amyloid $\beta$; PBS: Phosphate-buffered saline; PBS-T: PBS + Tween; PCR: Polymerase chain reaction

\section{Acknowledgements}

We want to thank Francis Blanche and his team at Sanofi for production of the different antibodies used in this report and Vincent Mikol and Nicolas Baudoin for the humanization of SAR228810 and the technical staff at Sanofi that performed the experimental work. These data were presented in part in a poster format at the AAIC2013, Boston (Pradier et al.) and AAIC2017, London (Taupin et al.). We would like to dedicate this manuscript to the memory of Thierry Canton who was a key driver of these studies.

\section{Funding}

Except for LK, HF and JR, all others have been full time employees of Sanofi at the time of their involvement for these studies and $L P, M D$, and $S N$ are inventors on a patent application describing SAR228810.

\section{Availability of data and materials}

The datasets used and/or analyzed during the current study are available from the corresponding author on reasonable request, subject to Sanofi policy.

\section{Authors' contributions}

LP was responsible for project design and global manuscript redaction. CC was the project head in the preclinical phase, and contributed to redaction. VB-B designed and performed the IHC in transgenic mice and was responsible for the specific design of the hemorrhage studies, and contributed to redaction. TD designed the IHC in transgenic mice. PBa designed the twophoton study and contributed to redaction. VT and PBer performed the invitro neurotoxicity assay and contributed to redaction. PD performed ex-vivo biochemistry assays. TC (in memorium) designed and performed in-vivo studies, and performed biochemical evaluation. JM organized and performed QPCR studies. AB organized electrophysiology studies and provided a major contribution to redaction and formatting. PBen designed and validated the immunotolerization study. BC organized lgG production. YS designed and performed the $\mathrm{IHC}$ studies in human samples, and contributed to redaction. $\mathrm{SN}$ designed and performed the $\mathrm{IHC}$ studies in human samples. MD designed and organized binding characterization, and co-led the discovery project. MG performed binding characterization. TW and TT performed binding characterization and contributed to redaction. DR designed and organized binding characterization. LK designed and performed two-photon in-vivo imaging and contributed to redaction. PBru and MS designed vascular liability studies and contributed to redaction. HF provided initial characterization of murine antibody. JR was the initiator of 13C3. All authors read and approved the final manuscript.

\section{Ethics approval}

Animal studies have been validated by an internal ethics committee (see Methods section).

Experiments were performed at Sanofi in an AAALAC-accredited facility in full compliance with the standards for the care and use of laboratory animals, according to French and European Community (Directive 2010/63/EU) legislation. All procedures were approved by the local Animal Ethics Committee (CEEA \#24) and the French Ministry for Research.

\section{Consent for publication}

Not applicable.

\section{Competing interests}

HK and JR are inventors on patent application W02009/065054 describing the murine antibody $13 \mathrm{C} 3$ from which the antibodies described in this manuscript are derived. Sanofi hold a license to the derived intellectual property. LK, Neurotar Ltd., performed this work as part of a research contract with Sanofi.

\section{Publisher's Note}

Springer Nature remains neutral with regard to jurisdictional claims in published maps and institutional affiliations.

\section{Author details}

${ }^{1}$ Sanofi R\&D Neuroscience Unit, Sanofi, 1Av P. Brossolette, 91385 Chilly-Mazarin, France. ${ }^{2}$ Sanofi R\&D Biotherapeutics Research, Vitry s/Seine, France. ${ }^{3}$ Sanofi R\&D Biotherapeutics Research, Framingham, USA. ${ }^{4}$ Neurotar Ltd., Helsinki, Finland. ${ }^{5}$ Sanofi R\&D Preclinical Safety, Alfortville, France. ${ }^{6}$ The Rockefeller University, New-York City, USA. ${ }^{7}$ Present address: Dyne Therapeutics, Inc., 400 Technology Square, Cambridge, USA. ${ }^{8}$ Present address: Laboratory for Lymphocyte Differentiation, RIKEN Center for Integrative Medical Sciences, Yokohama, Japan.

Received: 11 April 2018 Accepted: 4 November 2018

Published online: 28 November 2018

\section{References}

1. Holtzman DM, et al. Mapping the road forward in Alzheimer's disease. Sci Transl Med. 2011;3(114):114ps48.

2. Bertram L, Lill CM, Tanzi RE. The genetics of Alzheimer disease: back to the future. Neuron. 2010;68(2):270-81.

3. Jonsson T, et al. A mutation in APP protects against Alzheimer's disease and age-related cognitive decline. Nature. 2012;488(7409):96-9.

4. Liu J, et al. Antibody-based drugs and approaches against amyloid-beta species for Alzheimer's disease immunotherapy. Drugs Aging. 2016;33(10): $685-97$. 
5. MerckMSD, Merck announces discontinuation of APECS study evaluating verubecestat [MK-8931] for the treatment of people with prodromal Alzheimer's Disease. 2018.

6. Jack CR Jr, Holtzman DM. Biomarker modeling of Alzheimer's disease. Neuron. 2013;80(6):1347-58.

7. Sevigny J, et al. The antibody aducanumab reduces Abeta plaques in Alzheimer's disease. Nature. 2016;537(7618):50-6.

8. Bohrmann B, et al. Gantenerumab: a novel human anti-Abeta antibody demonstrates sustained cerebral amyloid-beta binding and elicits cellmediated removal of human amyloid-beta. J Alzheimers Dis. 2012;28(1):49-69.

9. Voyle $\mathrm{N}$, et al. The effect of low doses of gantenerumab on amyloid and tau biomarkers in cerebrospinal fluid (CSF) in the Marguerite Road Study. Alzheimer's Assoc Int Congr. 2018:Abst ID23224.

10. Eisai, Eisai and Biogen announce detailed results of phase II clinical study of BAN2401 in early Azheimer's disease at Alzheimer's Association International Conference (AAIC) 2018. 2018.

11. Ono K. Alzheimer's disease as oligomeropathy. Neurochem Int. 2017;119:57-70

12. McLean CA, et al. Soluble pool of Abeta amyloid as a determinant of severity of neurodegeneration in Alzheimer's disease. Ann Neurol. 1999;46(6):860-6.

13. Lue LF, et al. Soluble amyloid beta peptide concentration as a predictor of synaptic change in Alzheimer's disease. Am J Pathol. 1999;155(3):853-62.

14. Esparza TJ, et al. Amyloid-beta oligomerization in Alzheimer dementia versus high-pathology controls. Ann Neurol. 2013;73(1):104-19.

15. Shankar GM, et al. Amyloid-beta protein dimers isolated directly from Alzheimer's brains impair synaptic plasticity and memory. Nat Med. 2008; 14(8):837-42.

16. Jin $\mathrm{M}$, et al. Soluble amyloid beta-protein dimers isolated from Alzheimer cortex directly induce tau hyperphosphorylation and neuritic degeneration. Proc Natl Acad Sci U S A. 2011;108(14):5819-24.

17. Sehlin $D$, et al. Large aggregates are the major soluble Abeta species in AD brain fractionated with density gradient ultracentrifugation. PLOS One. 2012; 7(2):e32014.

18. Borlikova GG, et al. Alzheimer brain-derived amyloid beta-protein impairs synaptic remodeling and memory consolidation. Neurobiol Aging. 2013; 34(5):1315-27.

19. Esparza TJ, et al. Soluble amyloid-beta aggregates from human Alzheimer's disease brains. Sci Rep. 2016;6:38187.

20. Yang $T$, et al. Large soluble oligomers of amyloid beta-protein from Alzheimer brain are far less neuroactive than the smaller oligomers to which they dissociate. J Neurosci. 2017;37(1):152-63.

21. Brody DL, et al. Non-canonical soluble amyloid-beta aggregates and plaque buffering: controversies and future directions for target discovery in Alzheimer's disease. Alzheimers Res Ther. 2017;9(1):62.

22. Roberts BR, et al. Biochemically-defined pools of amyloid-beta in sporadic Alzheimer's disease: correlation with amyloid PET. Brain. 2017;140(5):1486-98.

23. Savage MJ, et al. A sensitive abeta oligomer assay discriminates Alzheimer's and aged control cerebrospinal fluid. J Neurosci. 2014;34(8):2884-97.

24. Yang T, et al. A highly sensitive novel immunoassay specifically detects low levels of soluble Abeta oligomers in human cerebrospinal fluid. Alzheimers Res Ther. 2015;7(1):14.

25. Schuster J, Funke SA. Methods for the specific detection and quantitation of amyloid-beta oligomers in cerebrospinal fluid. J Alzheimers Dis. 2016;53(1):53-67.

26. Mo JJ, et al. Efficacy and safety of anti-amyloid-beta immunotherapy for Alzheimer's disease: a systematic review and network meta-analysis. Ann Clin Transl Neurol. 2017:4(12):931-42.

27. Cummings $\mathrm{J}$, et al. ABBY: A phase 2 randomized trial of crenezumab in mild to moderate Alzheimer disease. Neurology. 2018;90(21):e1889-97.

28. Golde TE, Das P, Levites Y. Quantitative and mechanistic studies of Abeta immunotherapy. CNS Neurol Disord Drug Targets. 2009;8(1):31-49.

29. Schupf $N$, et al. Peripheral Abeta subspecies as risk biomarkers of Alzheimer's disease. Proc Natl Acad Sci U S A. 2008;105(37):14052-7.

30. Reddy MP, et al. Elimination of Fc receptor-dependent effector functions of a modified lgG4 monoclonal antibody to human CD4. J Immunol. 2000; 164(4):1925-33.

31. Bard F, et al. Peripherally administered antibodies against amyloid betapeptide enter the central nervous system and reduce pathology in a mouse model of Alzheimer disease. Nat Med. 2000;6(8):916-9.

32. Johansson AS, et al. Physiochemical characterization of the Alzheimer's disease-related peptides A beta 1-42Arctic and A beta 1-42wt. FEBS J. 2006; 273(12):2618-30
33. Stine WB Jr, et al. In vitro characterization of conditions for amyloid-beta peptide oligomerization and fibrillogenesis. J Biol Chem. 2003;278(13): 11612-22.

34. Blanchard $V$, et al. Time sequence of maturation of dystrophic neurites associated with Abeta deposits in APP/PS1 transgenic mice. Exp Neurol. 2003;184(1):247-63.

35. Dewachter I, et al. Aging increased amyloid peptide and caused amyloid plaques in brain of old APP N717/ transgenic mice by a different mechanism than mutant presenilin1. J Neurosci. 2000;20(17):6452-8.

36. Holtmaat $A$, et al. Long-term, high-resolution imaging in the mouse neocortex through a chronic cranial window. Nat Protoc. 2009;4(8):1128-44.

37. Burgold $\mathrm{S}$, et al. In vivo multiphoton imaging reveals gradual growth of newborn amyloid plaques over weeks. Acta Neuropathol. 2011;121(3): 327-35.

38. Wilde DB, et al. Evidence implicating L3T4 in class II MHC antigen reactivity; monoclonal antibody GK1.5 (anti-L3T4a) blocks class II MHC antigen-specific proliferation, release of lymphokines, and binding by cloned murine helper T lymphocyte lines. J Immunol. 1983;131(5):2178-83.

39. Alters SE, et al. Mechanisms of anti-CD4-mediated depletion and immunotherapy. A study using a set of chimeric anti-CD4 antibodies. J Immunol. 1990;144(12):4587-92.

40. Racke MM, et al. Exacerbation of cerebral amyloid angiopathy-associated microhemorrhage in amyloid precursor protein transgenic mice by immunotherapy is dependent on antibody recognition of deposited forms of amyloid beta. J Neurosci. 2005;25(3):629-36.

41. Ghiso J, et al. Systemic catabolism of Alzheimer's Abeta40 and Abeta42. J Biol Chem. 2004;279(44):45897-908.

42. Kastanenka KV, et al. Immunotherapy with aducanumab restores calcium homeostasis in Tg2576 mice. J Neurosci. 2016;36(50):12549-58.

43. Beckmann $\mathrm{N}$, et al. Noninvasive magnetic resonance imaging detection of cerebral amyloid angiopathy-related microvascular alterations using superparamagnetic iron oxide particles in APP transgenic mouse models of Alzheimer's disease: application to passive Abeta immunotherapy. J Neurosci. 2011;31(3):1023-31.

44. Fuller JP, et al. Comparing the efficacy and neuroinflammatory potential of three anti-abeta antibodies. Acta Neuropathol. 2015;130(5):699-711.

45. Ryman JT, Meibohm B. Pharmacokinetics of monoclonal antibodies. CPT Pharmacometrics Syst Pharmacol. 2017;6(9):576-88.

46. Blennow K, et al. Effect of immunotherapy with bapineuzumab on cerebrospinal fluid biomarker levels in patients with mild to moderate Alzheimer disease. Arch Neurol. 2012;69(8):1002-10.

47. Gertz MA, Landau HJ, Weiss BM. Organ response in patients with AL amyloidosis treated with NEOD001, an amyloid-directed monoclonal antibody. Am J Hematol. 2016;91(12):E506-8.

48. AlzForumNews, High-dose gantenerumab lowers plaque load. 2017.

49. Sperling RA, et al. Amyloid-related imaging abnormalities in amyloid-modifying therapeutic trials: recommendations from the Alzheimer's Association Research Roundtable Workgroup. Alzheimers Dement. 2011;7(4):367-85.

50. Bacskai BJ, et al. Non-Fc-mediated mechanisms are involved in clearance of amyloid-beta in vivo by immunotherapy. J Neurosci. 2002;22(18):7873-8.

51. Tamura $Y$, et al. The $F(a b)^{\prime} 2$ fragment of an Abeta-specific monoclonal antibody reduces Abeta deposits in the brain. Neurobiol Dis. 2005;20(2):541-9.

52. Levites $Y$, et al. Intracranial adeno-associated virus-mediated delivery of antipan amyloid beta, amyloid beta40, and amyloid beta42 single-chain variable fragments attenuates plaque pathology in amyloid precursor protein mice. J Neurosci. 2006;26(46):11923-8.

53. Das $P$, et al. Amyloid-beta immunization effectively reduces amyloid deposition in FcRgamma-/- knock-out mice. J Neurosci. 2003;23(24):8532-8.

54. Wilcock DM, et al. Deglycosylated anti-amyloid-beta antibodies eliminate cognitive deficits and reduce parenchymal amyloid with minimal vascular consequences in aged amyloid precursor protein transgenic mice. J Neurosci. 2006;26(20):5340-6.

55. Adolfsson $\mathrm{O}$, et al. An effector-reduced anti-beta-amyloid (Abeta) antibody with unique abeta binding properties promotes neuroprotection and glial engulfment of Abeta. J Neurosci. 2012;32(28):9677-89.

56. Delnomdedieu $M$, et al. First-In-Human safety and long-term exposure data for AAB-003 (PF-05236812) and biomarkers after intravenous infusions of escalating doses in patients with mild to moderate Alzheimer's disease. Alzheimers Res Ther. 2016;8(1):12.

57. Yirmiya R, Goshen I. Immune modulation of learning, memory, neural plasticity and neurogenesis. Brain Behav Immun. 2011;25(2):181-213. 
58. Lee $\mathrm{SH}$, et al. Antibody-mediated targeting of tau in vivo does not require effector function and microglial engagement. Cell Rep. 2016;16(6):1690-700.

59. Cohen SI, et al. Proliferation of amyloid-beta42 aggregates occurs through a secondary nucleation mechanism. Proc Natl Acad Sci U S A. 2013:110(24):9758-63.

60. Condello C, et al. Microglia constitute a barrier that prevents neurotoxic protofibrillar Abeta42 hotspots around plaques. Nat Commun. 2015;6:6176.

61. Wang A, et al. Robust amyloid clearance in a mouse model of Alzheimer's disease provides novel insights into the mechanism of amyloid-beta immunotherapy. J Neurosci. 2011;31(11):4124-36.

62. Jacobsen $\mathrm{H}$, et al. Combined treatment with a BACE inhibitor and antiAbeta antibody gantenerumab enhances amyloid reduction in APPLondon mice. J Neurosci. 2014;34(35):11621-30.

Ready to submit your research? Choose BMC and benefit from:

- fast, convenient online submission

- thorough peer review by experienced researchers in your field

- rapid publication on acceptance

- support for research data, including large and complex data types

- gold Open Access which fosters wider collaboration and increased citations

- maximum visibility for your research: over $100 \mathrm{M}$ website views per year

At BMC, research is always in progress.

Learn more biomedcentral.com/submissions 